\title{
Apocynin reduces blood pressure and restores the proper function of vascular endothelium in SHR
}

\author{
Ligia A. Perassa ${ }^{a, b, 1}$, Murilo E. Graton a,b,1 ${ }^{\text {, Simone R. Potje }}{ }^{\mathrm{a}, \mathrm{b}, 1}$, Jéssica A. Troiano ${ }^{\mathrm{a}, \mathrm{b}, 1}$, Mariana S. Lima ${ }^{\mathrm{b}}$, \\ Gabriel T. Vale ${ }^{c}$, Ariana A.F. Pereira ${ }^{\mathrm{a}, \mathrm{b}}$, Ana Claúdia M.S. Nakamune ${ }^{\mathrm{a}, \mathrm{b}}$, Doris H. Sumida ${ }^{\mathrm{a}, \mathrm{b}}$, Carlos R. Tirapelli ${ }^{\mathrm{c}}$, \\ Lusiane M. Bendhack ${ }^{\mathrm{d}}$, Cristina Antoniali ${ }^{\mathrm{a}, \mathrm{b}, *}$ \\ a Multicenter Graduate Program in Physiological Sciences, SBFis, Brazil \\ ${ }^{\mathrm{b}}$ Department of Basic Sciences, School of Dentistry of Araçatuba, UNESP - Univ Estadual Paulista, Araçatuba, São Paulo, Brazil \\ c Department of Psychiatry Nursing and Human Sciences, College of Nursing of Ribeirão Preto, USP - University of São Paulo, Ribeirão Preto, São Paulo, Brazil \\ d Department of Physics and Chemistry. Faculty of Pharmaceutical Sciences of Ribeirão Preto, USP - University of São Paulo, Ribeirão Preto, São Paulo, Brazil
}

\section{A R T I C L E I N F O}

\section{Article history:}

Received 24 February 2016

Received in revised form 6 May 2016

Accepted 18 June 2016

Available online 25 June 2016

\section{Keywords:}

Apocynin

SHR

Endothelial dysfunction

eNOS

Reactive oxygen species

\begin{abstract}
A B S T R A C T
This study has evaluated how the vascular endothelium of hypertensive rats chronically treated with apocynin affects acetylcholine (ACh), sodium nitroprusside (SNP), and phenylephrine (PE) action on the nitric oxide (NO) signal transduction pathway in endothelial (EC) and vascular smooth muscle cells. Treatment with apocynin significantly reduced the mean arterial pressure in spontaneously hypertensive rats (SHR). In addition, apocynin improved the impaired ACh hypotensive effect on SHR. Although systemic oxidative stress was high in SHR, SHR treated with apocynin and normotensive rats presented similar systemic oxidative stress levels. Endothelium significantly blunted PE contractions in intact aortas of treated SHR. The ACh effect was impaired in resistance arteries and aortas of SHR, but this same effect was improved in treated SHR. The SNP potency was higher in intact resistance arteries of treated SHR than in intact resistance arteries of untreated SHR. NO and calcium concentrations increased, whereas reactive oxygen species levels decreased in EC of treated SHR. Aortas of untreated and treated SHR did not differ in terms of SGC alpha or beta units expression. Aorta of treated SHR expressed higher eNOS levels as compared to aorta of untreated SHR. The study groups did not differ with respect to NOX1, NOXO1, or NOX4 expression. However, treatment with apocynin normalized overexpression of NOX2 and its subunit p47phox in aortas of SHR. Based on all the results presented in this study, we suggest apocynin increases NO biovailability by different mechanisms, restoring the proper function of vascular endothelium in SHR.
\end{abstract}

(c) 2016 Elsevier Inc. All rights reserved.

\section{Introduction}

Reactive oxygen species (ROS) contribute to the pathogenesis of numerous cardiovascular diseases and conditions including hypertension [1]. NAD (P)H oxidase (NOX) is an enzyme complex [2] that has been considered a major ROS source in vascular cells [3]. Moreover, the NOX1, NOX2, and NOX4 subunits are highly expressed in these cells, and their activity increases during hypertension [4-7]. NOX reduces oxygen $\left(\mathrm{O}_{2}\right)$ by addition of one electron, to generate the superoxide anion $\left(\mathrm{O}_{2}^{-}\right) \cdot \mathrm{O}_{2}^{-}$ can interfere with the signal transduction mechanisms of vascular

\footnotetext{
DOI of original article: http://dx.doi.org/10.1016/j.vph.2016.08.006.

* Corresponding author at: Faculdade de Odontologia de Araçatuba-UNESP/ Departamento de Ciências Básicas, Rua: José Bonifácio, 1193 - CEP 16015-050, Araçatuba, São Paulo, Brazil.

E-mail address: crisant@foa.unesp.br (C. Antoniali).

1 These authors contributed equally to this study.
}

smooth muscle relaxation mediated by nitric oxide (NO) [8]. $\mathrm{O}_{2}^{-}$reacts with $\mathrm{NO}$, to form peroxynitrite $\left(\mathrm{ONOO}^{-}\right)[9,10]$, a species that participates in endothelial dysfunction [11]. $\mathrm{ONOO}^{-}$also accounts for indirect NO synthase (NOS) coupling, which increases $\mathrm{O}_{2}^{-}$production [12].

Increased NOX activity and $\mathrm{O}_{2}^{-}$production occurs in aorta of spontaneously hypertensive rats (SHR) as compared to aorta of normotensive Wistar-Kyoto rats $[6,13]$. This could be associated with impaired endothelium-dependent vascular smooth muscle relaxation in SHR [14-16]. NOX activity could contribute to vascular diseases in hypertension, which has prompted investigations into the antihypertensive effects of unspecific NOX inhibitors, like apocynin [17,18].

Myeloperoxidase (MPO), which is present in phagocytic cells, metabolizes apocynin, to produce an active metabolite, diapocynin [19]. Diapocynin may inhibit phosphorylation of the NAD(P)H oxidase complex and translocation of its cytosolic components (p47phox, p67phox) to the membrane, thereby blocking its activity [19-21]. Because endothelial cells (EC) and vascular smooth muscle cells (VSMC) do not contain MPO, apocynin could act by a MPO-independent pathway like 
antioxidant or radical scavenging $[23,24]$ even though EC could internalize MPO via action of a specific enzyme [22].

Chronic treatment of SHR with apocynin has led to inconclusive results regarding blood pressure. Bäumer et al. [25] demonstrated reduced systolic blood pressure (SBP) in SHR treated with apocynin for 28 days. Schlüter et al. [26] pointed out that apocynin failed to lower arterial pressure in SHR. More recently, Tain et al. [27] showed that chronic treatment of SHR with apocynin from the 4th-12th week of life attenuated but did not prevent hypertension.

The mechanisms underlying the apocynin antihypertensive effect on SHR are not fully understood. Apocynin might reduce p47phox translocation in kidney tissue, preventing oxidative stress in the kidney of SHR. However, apocynin cannot decrease asymmetric dimethylarginine (ADMA), an endogenous NO synthase inhibitor, in the plasma, kidney, or heart of SHR. Apocynin cannot increase the L-Arg/ADMA ratio in plasma or kidney, either, suggesting that this unspecific NOX inhibitor might not improve systemic NO biovailability [27] in SHR. Reduced ROS levels as well as increased NO production and endothelial nitric oxide synthase (eNOS) activity occurred in aortic segments of SHR treated with apocynin, suggesting that apocynin could improve the impaired $\mathrm{NO} / \mathrm{O}_{2}^{-}$balance associated with hypertension. However, nifedipine-treated SHR provided comparable results [25]. Moreover, apocynin did not inhibit vascular $\mathrm{NAD}(\mathrm{P}) \mathrm{H}$-oxidase-dependent $\mathrm{O}_{2}^{-}$formation, and its vasodilating effect on distal interlobar arteries or coronary arteries of apocynin-treated SHR could be partially due to inhibited Rho kinase activity [26].

Preliminary results obtained in our laboratory showed that chronic treatment with apocynin increased the acethylcholine (ACh) hypotensive and aorta vasodilating effects in SHR, but not in Wistar rats. These results led us to hypothesize that apocynin might restore endothelium modulation of blood pressure and vascular reactivity to vasoconstrictors and vasodilators agonists in hypertensive rats. Therefore, this study has evaluated how the vascular endothelium of hypertensive rats chronically treated with apocynin affects the ACh, sodium nitroprusside (SNP), and phenylephrine (PE) action. Moreover, this study has attempted to elucidate how in vivo treatment with apocynin may alter NO biovailability in vascular cells of hypertensive rats. We have also analyzed how treatment with apocynin in SHR modifies eNOS and subsequent signaling events as well as NOX isoforms expression. More specifically, we have investigated how treatment with apocynin (six weeks) in SHR affects the endothelial function, the $\mathrm{Ca}^{2+}$, NO, and ROS endothelial concentration, and the expression of eNOS and NO targets like the soluble guanylyl cyclase (sGC) alpha $(\alpha)$ and beta $(\beta)$ subunits in vascular cells. Further analysis included expression of the $\mathrm{NAD}(\mathrm{P}) \mathrm{H}$ oxidase subunits NOX1, NOXO1, NOX2, p47phox, and NOX4.

\section{Materials and methods}

The Animal Research Ethics Committee of the School of Dentistry of Araçatuba-UNESP approved all the experiments conducted in this study (CEEA-FOA/UNESP, protocol. 01561-2011).

\subsection{Animals}

Male SHR and male normotensive Wistar rats were used in this study. The animals received standard chow and water ad libitum and were kept under controlled temperature $\left(22-24{ }^{\circ} \mathrm{C}\right)$ in a 12 -hour light/dark cycle. SBP was verified by tail plethysmography (PowerLab, ADInstruments, Melbourne, Australia) before, during, and after treatment. Untreated SHR with SBP higher than $150 \mathrm{mmHg}$ were used as controls. The animals were treated with apocynin from the fourth to the tenth week of life (30 mg/kg, diluted in drinking water) [28]. Every week, the rats were weighed, and the apocynin dose was adjusted. At the end of the 6th week of treatment, the rats were used in the experiments described below.

\subsection{Systemic oxidative stress determination}

At the end of the treatment, all the groups of rats were decapitated. Blood was collected from each animal separately in glass tubes containing heparin and centrifuged (Centrifuge 5810R, rotor S-4-104, Eppendorf, Hamburg, Germany) at $4{ }^{\circ} \mathrm{C}$ and $1000 \mathrm{rpm}$ for $15 \mathrm{~min}$. Plasma was removed by aspiration, and erythrocytes were washed with sodium chloride solution $0.15 \mathrm{~mol} / \mathrm{L}$ three times. Hemolysates were prepared (1:10) by addition of magnesium sulfate $4 \mathrm{mmol} / \mathrm{L}$ and acetic acid $1 \mathrm{mmol} / \mathrm{L}$ mixed with $1 \mathrm{~mL}$ of trichloroacetic acid $10 \%$, which caused proteins to precipitate, and centrifuged again (3 min at $1000 \mathrm{rpm}$ ). Then, $1 \mathrm{~mL}$ of thiobarbituric acid $0.67 \%$ was added [29]. Samples were heated in boiling water for $15 \mathrm{~min}$, and the amount of thiobarbituric acid reactive species (TBARS) was determined based on the absorbance at $535 \mathrm{~nm}$, recorded on a spectrophotometer (Hitachi U1100, Tokyo, Japan) as described previously [30]. Lipid peroxidation levels were identified in erythrocytes through substances that reacted with 2-thiobarbituric acid. By using the molar extinction coefficient of this acid $\left(\varepsilon=1.56 \times 10^{5} \mathrm{~mol} / \mathrm{L}^{-1} \mathrm{~cm}^{-1}\right)$, results were expressed in $\mathrm{nmol} / \mathrm{mg}$ of protein. Proteins were measured by using the method of Lowry et al. [31] with bovine serum albumin as standard.

\subsection{In vivo studies}

\subsubsection{Cannulation}

Rats were anesthetized with intraperitoneal ketamine $(45 \mathrm{mg} / \mathrm{kg}$ ) combined with xylazine $(5 \mathrm{mg} / \mathrm{kg}$ ). With the animals under anesthesia, a polyethylene cannula $\left(\mathrm{PE}_{10}\right.$ connected to $\mathrm{PE}_{50}$-Intramedic Polyethylene Tubing, BD Company, New Jersey, USA) filled with heparinized saline $0.15 \mathrm{~mol} / \mathrm{L}$ was inserted into the abdominal aorta, through the femoral artery, to record the arterial pressure, and another cannula was inserted into the femoral vein for drug administration. The cannulae were passed under the skin and externalized in the dorsal region of the animal. After surgery, the animals were kept in individual cages; standard chow and water were offered ad libitum.

\subsubsection{Mean arterial pressure (MAP) and heart rate (HR) measurement}

At the end of the 6th week of treatment, MAP, SBP, diastolic blood pressure (DBP), and HR were continuously recorded in conscious rats by using a pressure transducer and an amplifier (ADInstruments, Melbourne, Australia) attached to the intra-arterial cannula. MAP before and after drug administration was calculated by using the LabChart 7 software (ADInstruments, Melbourne, Australia), in which the BP variation was obtained.

\subsubsection{Experimental protocol}

After 30 min were allowed for BP stabilization, ACh (2 and $10 \mu \mathrm{g} / \mathrm{kg}$ ) or SNP (10 and $35 \mu \mathrm{g} / \mathrm{kg}$ ) was intravenously injected in bolus, and drug effects were recorded until the response stabilized. With the aid of the LabChart 7 software, the MAP variation ( $\mathrm{MAP}$ ) was calculated based on the difference between MAP values at basal condition and at the maximum hypotensive effect after drug administration. These values were then transformed into percentage (\% $\triangle \mathrm{MAP})$. The results are expressed as mean \pm standard error of the mean (SEM) values for MAP and HR.

\subsection{In vitro studies}

\subsubsection{Vascular reactivity on aorta artery (conductance vessels)}

After decapitation, the thoracic aorta of each animal was removed, dissected, and sectioned in 4-mm rings. Some rings had their endothelium preserved $(\mathrm{E}+)$, whereas others had their endothelium mechanically removed $(\mathrm{E}-)$. The rings were kept in two stainless steel stirrups and connected to an isometric force transducer (Letica Scientific Instruments, Barcelona, Spain) in a chamber containing Krebs solution (composition, in mmol/L: $\mathrm{NaCl} 130.0 ; \mathrm{KCl}$ 4.7; $\mathrm{KH}_{2} \mathrm{PO}_{4} 1.2 ; \mathrm{MgSO}_{4} 1.2$; 
$\mathrm{NaHCO}_{3} 14.9 ; \mathrm{C}_{6} \mathrm{H}_{12} \mathrm{O}_{6} 5.5 ; \mathrm{CaCl}_{2}$ 1.6), $\mathrm{pH}$ 7.4, supplied with gas containing $95 \% \mathrm{O}_{2}$ and $5 \% \mathrm{CO}_{2}$ at $37{ }^{\circ} \mathrm{C}$. Each ring was stretched to a resting tension of $2.0 \mathrm{~g}$, which was maintained for $60 \mathrm{~min}$ for stabilization. During this period, the rings were washed three times with Krebs solution. To test functional integrity, the rings were stimulated with potassium chloride at high concentration $(\mathrm{KCl} 120 \mathrm{mmol} / \mathrm{L})$ for $15 \mathrm{~min}$; then, they were washed until stabilization was achieved again. The rings that presented contraction $>1.5 \mathrm{~g}$ were considered viable. Next, the rings were stimulated with PE $(0.1 \mu \mathrm{mol} / \mathrm{L})$, and the presence or absence of endothelium was verified by using ACh $(1 \mu \mathrm{mol} / \mathrm{L})$. Rings with $>70 \%$ relaxation to ACh were placed in the $\mathrm{E}+$ group, and rings with $<10 \%$ relaxation were placed in the E- group. Cumulative concentration-effect curves were constructed for $\mathrm{PE}(0.1 \mathrm{nmol} / \mathrm{L}-10 \mu \mathrm{mol} / \mathrm{L})$ acting on $\mathrm{E}+$ and $\mathrm{E}-$ rings and for $\mathrm{ACh}(0.1 \mathrm{nmol} / \mathrm{L}-10 \mu \mathrm{mol} / \mathrm{L})$ acting on $\mathrm{E}+$ rings.

\subsubsection{Vascular reactivity on mesenteric artery (resistance vessels)}

After decapitation, mesentery was removed and placed in a petri dish containing Krebs solution $\left(4{ }^{\circ} \mathrm{C}\right)$. Then, the second and third branches of mesenteric arteries were isolated, dissected, and cut into 2-mm rings after two tungsten wires $(40 \mu \mathrm{m})$ were passed through the interior of the vessel with the aid of a stereomicroscope (Luxeo 2S, Labomed, Los Angeles, USA). The experiment was carried out carefully to keep the vessel endothelium, and it was mounted according to the method described by Mulvany and Halpern [32]. After 30 min stabilization in Krebs solution and oxygenation at $37^{\circ} \mathrm{C}$ and $\mathrm{pH} 7.4$, segments were stretched to their optimal lumen diameter, to develop active tension. This was determined based on the internal circumference/wall tension ratio of the segments their internal circumference was set to $90 \%$ of the circumference the vessels would have if they were exposed to a passive tension equivalent to the tension produced by a transmural pressure of $100 \mathrm{mmHg}$. The employed vessels had internal diameter of $<300 \mu \mathrm{m}$ [32]. Segments were washed and left to equilibrate for $30 \mathrm{~min}$. Then, the viability of the vessels stimulated with high potassium chloride concentration $(120 \mathrm{mmol} / \mathrm{L})$ was tested. Vessels that maintained contraction higher than $6 \mathrm{mN}$ were considered viable. The presence of endothelium was confirmed by $70 \%$ relaxation to ACh $(0.1 \mathrm{~mol} / \mathrm{L})$; $10 \%$ relaxation corresponded to absence of endothelium in vessels pre-contracted with PE $(0.1 \mu \mathrm{mol} / \mathrm{L})$. Cumulative concentration-effect curves were constructed for SNP $(0.1 \mathrm{nmol} / \mathrm{L}-100 \mu \mathrm{mol} / \mathrm{L})$ and for ACh ( $0.1 \mathrm{nmol} / \mathrm{L}-10 \mu \mathrm{mol} / \mathrm{L})$.

\subsection{Flow cytometry}

\subsubsection{Endothelial cells (EC) isolation from rat aorta}

At 10 weeks, animals were anesthetized in a chamber saturated with isoflurane and killed by decapitation. The thoracic aorta $(15 \mathrm{~mm})$ was dissected from the adjacent tissue, cut longitudinally, and maintained in modified Hanks solution (composition, in mmol/L: $\mathrm{CaCl}_{2}, 1.6$; $\mathrm{MgCl}_{2}, 1.0 ; \mathrm{NaCl}, 120.0 ; \mathrm{KCl}, 5.0 ; \mathrm{NaH}_{2} \mathrm{PO}_{4}, 0.5$; dextrose, 10.0; and HEPES, 10.0, pH 7.4). EC cells were mechanically removed with the aid of a flat plastic rod. The obtained cell suspension was centrifuged (1000 rpm for $5 \mathrm{~min}$ ) at room temperature, concentrated in $250 \mu \mathrm{L}$ of Hanks solution, and separated into polystyrene tubes for flow cytometry. After this step, the cells remained in Hanks solution at $37{ }^{\circ} \mathrm{C}$ until the experiment [33]. The number of experiments referred to EC obtained from one aorta. A total of 2500 events (cells) were analyzed by flow cytometry (ATTUNE Acoustic Focusing Cytometer ${ }^{\circledR}$, Applied Biosystem, Waltham, USA) using specific probes for $\mathrm{Ca}^{2+}$ (Fluo-3AM), NO (DAF-2/ DA), and ROS (DHE) according to the experimental protocols described below.

2.5.2. Cytosolic calcium $\left(\left[\mathrm{Ca}^{2+}\right]_{c}\right)$, nitric oxide $\left([\mathrm{NO}]_{c}\right)$, and reactive oxygen species $\left([R O S]_{c}\right)$ concentration

After the baseline fluorescence emission (blank) was verified, the EC suspension was incubated with Fluo-3AM ( $5 \mu \mathrm{mol} / \mathrm{L}$ ), to determine $\left[\mathrm{Ca}^{2+}\right]_{\mathrm{c}}$, or DAF-2/DA $(10 \mu \mathrm{mol} / \mathrm{L})$, to determine $[\mathrm{NO}]_{\mathrm{c}}$, for $20 \mathrm{~min}$, followed by excitation with blue laser at $488 \mathrm{~nm}$ with emission of $530 / 30$. As for $[R O S]_{c}$ determination, the fluorescent probe DHE $(2.5 \mathrm{mmol} / \mathrm{L})$ was employed, and the sample was excited with blue laser at $488 \mathrm{~nm}$ with emission of 585/42. A total of 2500 events were acquired for each protocol. The intensity of the emitted fluorescence was detected in the absence (baseline) or presence of ACh $(1 \mu \mathrm{mol} / \mathrm{L})$, and the values were expressed as the increase in the fluorescence intensity as compared to baseline values. The median fluorescence intensity was measured in all the samples by using Attune Cytometric Software (Applied Biosystem, Waltham, USA) and compared between the groups. Cytofluorographic tracings generated by the software were analyzed after reading of data from the cytometer. Results are presented as the mean of the medians of fluorescence intensity from the cells.

\subsection{Western blotting}

Thoracic aorta segments were removed from the animals, dissected, immediately pulverized and frozen in liquid nitrogen, and stored at $-80^{\circ} \mathrm{C}$. Tissues were macerated in liquid nitrogen and homogenized separately in RIPA buffer (supplemented with a cocktail of protease inhibitors) by using a sonicator (Vibra Cell Sonics, Newtown, USA). The homogenates were centrifuged $\left(4^{\circ} \mathrm{C}, 4000 \mathrm{rpm}\right.$, for $15 \mathrm{~min}$ ) to separate the supernatant. The protein dosage in the supernatant was determined by the method described by Lowry et al. [31]; bovine serum albumin was used as standard. One hundred micrograms (100 $\mu \mathrm{g})$ of total protein was subjected to electrophoresis in $8 \%$ or $10 \%$ polyacrylamide gel (based on the molecular weight of each protein) and transferred to the nitrocellulose membrane. After transfer, the membranes were blocked with $5 \%$ skimmed milk in Tris buffer at room temperature for $30 \mathrm{~min}$. Next, the membranes were incubated with primary antibodies for the $\alpha(1: 500)$ and $\beta(1: 500)$ subunits of sGC, eNOS $(1: 2500)$, NOX1 (1:250), NOXO1 (1:500), NOX2 (1:250), p47phox (1:500), and NOX4 (1:2000) at $4{ }^{\circ} \mathrm{C}$ overnight. Then, the membranes were incubated with anti-rabbit secondary antibody (1:1000) at room temperature for $1 \mathrm{~h}$. The membranes were finally incubated with the chemiluminescent substrate for peroxidase and exposed to radiographic film for detection of the bands. $\beta$-actin was used to normalize the results. The intensity of the bands was quantified by optical densitometry software, Scion (Scion Image beta 3b Release, National Institutes of Health, Frederick, USA).

\subsection{Drugs and reagents}

Apocynin (4-Hydroxy-3-methoxyacetophenon 98\%), ACh (Acetylcholine chloride), SNP (Sodium nitroprusside), PE (L-phenylephrine hydrochloride), Fluo-3AM, 4.5-diaminofluorescein (DAF-2/DA), dihydroethidium (DHE), eNOS antibody (anti-eNOS, SAB: 4502013), sGC $\alpha$ subunit antibody (anti-GUCY1A2, SAB: 1300812), sGC $\beta$ subunit antibody (anti- $\beta$ guanylate cyclase, SAB: 4501344), and $\beta$-actin antibody (A5441) were obtained from Sigma Aldrich (St Louis, USA). NOX1 (SC5821), NOXO1 (SC292094), NOX2 (SC5827), p47phox (SC14015), and NOX4 (SC30141) were acquired from Santa Cruz Biotechnology (Dallas, USA). The remaining salts and reagents were purchased from Sigma Aldrich (St Louis, MO, USA) and GE Healthcare (Piscataway, NJ, USA).

\subsection{Statistical analysis}

The results of the in vivo and in vitro experiments were expressed as the mean \pm SEM and compared between groups (Wistar and SHR, untreated or treated with apocynin) by using the repeated-measure analysis of variance (Two-away ANOVA) and Tukey post-hoc test. Differences between the groups were considered significant when $\mathrm{p}<0.05$. 


\section{Results and discussion}

3.1. Treatment with apocynin does not change rat weight or naso-anal length

The weight and naso-anal length (Fig. 1A and B) of the animals increased significantly during the six weeks of treatment. The weight and naso-anal length of untreated and treated SHR were lower than the weight and naso-anal length of normotensive Wistar rats, and apocynin did not alter these parameters. In previous works, treatment with apocynin did not modify the body weight in normotensive or hypertensive angiotensin (Ang) II-infused mice [34], or the heart weight or left kidney weight/100 g of body weight in normotensive rats or SHR [27]. Therefore, chronic treatment of normotensive and hypertensive rodents with apocynin does not change body parameters, suggesting that apocynin does not interfere in the development of treated animals.

\subsection{Apocynin reduces systemic oxidative stress in SHR}

TBARS levels were evaluated in erythrocytes of untreated and treated Wistar rats or SHR (Fig. 2). SHR $(86.3 \pm 3.5, \mathrm{n}=5)$ presented increased lipid peroxidation as compared to Wistar rats $(68.2 \pm 3.5$, $\mathrm{n}=5$ ), indicating the presence of higher systemic oxidative damage in SHR. Plasma biomarkers of cell damage due to systemic oxidative stress are elevated in patients with hypertension [35].

Chronic treatment with apocynin decreased oxidative damage in both Wistar $(56.5 \pm 3.3, \mathrm{n}=5)$ rats and SHR $(59.8 \pm 2.1, \mathrm{n}=5)$, without differences between untreated and treated rats. Treatment with apocynin prevented oxidative stress in the kidney of SHR because it
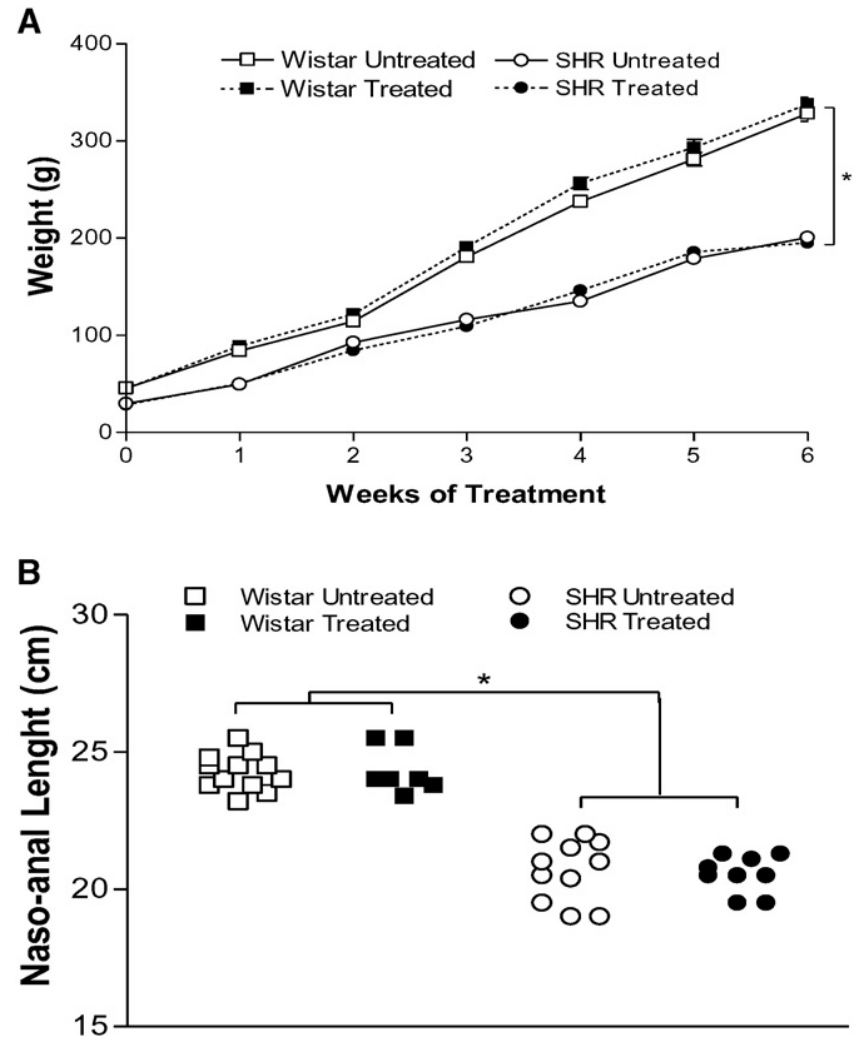

Fig. 1. (A) Weight, in grams, during the weeks of treatment with apocynin $(30 \mathrm{mg} / \mathrm{Kg})$ and (B) Naso-anal Length, in centimeters, at the end of treatment for all the experimental groups (white square indicates untreated Wistar rats; black square indicates treated Wistar rats; white circle indicates untreated SHR; and black square indicates treated SHR). Values represent the mean \pm SEM of the results, $n=7-13$. ${ }^{*} \mathrm{p}<0.05$ untreated and treated Wistar rats versus untreated and treated SHR (ANOVA).

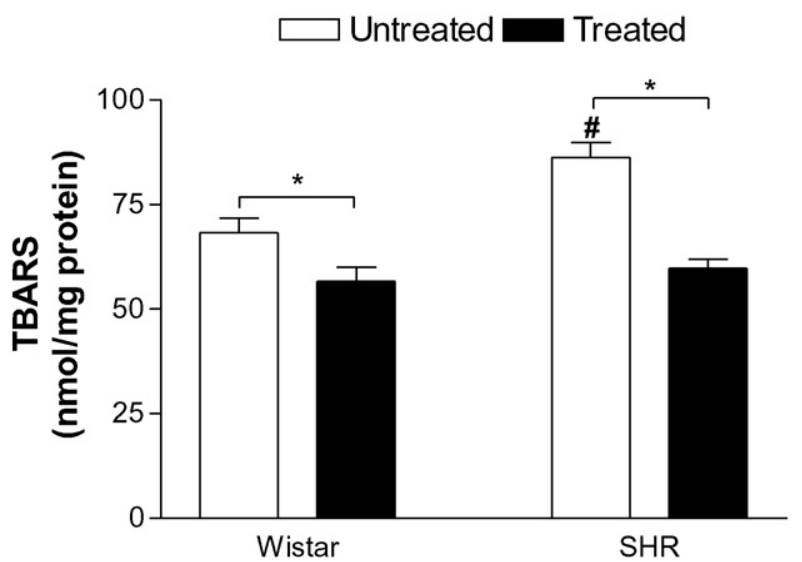

Fig. 2. Determination of systemic oxidative stress, in $\mathrm{nmol} / \mathrm{mg}$ of protein, based on 2thiobarbituric acid reactive species (TBARS) concentration in erythrocyte samples from Wistar and SHR untreated (white bars) and treated (black bars) with apocynin (30 mg/ $\mathrm{Kg}$ ). Values represent the mean \pm SEM of the results, $\mathrm{n}=5$. ${ }^{*} \mathrm{p}<0.05$ untreated versus treated rats; ${ }^{\#} \mathrm{p}<0.05$ untreated SHR versus other groups (ANOVA).

reduced p47phox translocation and 8-OHdG immunostaining [27]. Apocynin has been described to inhibit phorbol myristate acetate (PMA)-stimulated $\mathrm{O}_{2}^{-}$production in human leucocytes and hepatic lipid peroxidation induced by intermittent hypoxia in rats $[23,36]$. Based on these data, treatment with apocynin effectively reduces systemic ROS in SHR.

\subsection{Apocynin reduces $M A P, H R, S B P$, and $D B P$ values in $S H R$}

Several factors can increase BP in SHR, including oxidative stress. Small alterations in BP levels in normotensive rats occur in the first weeks after birth [37]. In SHR, BP increases mainly between the 3rd and 10th week of life, and its level is about 30\% higher than the BP level in normotensive rats [38]. According to Dickhout and Lee [39], HR in SHR is already increased in the first weeks of life as compared to normotensive rats. Based on these observations, we initiated treatment of SHR with apocynin in the fourth week (22 days old) and continued it until the tenth week to prevent development of hypertension.

MAP, HR, SBP, and DBP values were higher in SHR as compared to normotensive Wistar rats (Fig. 3A, B, C and D, respectively). Moreover, SBP and DBP (Fig. $3 C$ and D) in SHR treated with apocynin (SBP, $148.2 \pm 1.0$; DBP, $100.1 \pm 0.8 \mathrm{mmHg} / \mathrm{min}$; $\mathrm{n}=7$ ) were lower than SBP and DBP in untreated SHR (SBP, $180.6 \pm 2.4$; DBP, $132.9 \pm$ $0.9 \mathrm{mmHg} / \mathrm{min} ; \mathrm{n}=7$ ). At the end of the 6 th week of treatment, MAP was significantly reduced in treated SHR $(129.5 \pm 2.2 \mathrm{mmHg}, \mathrm{n}=9)$ as compared to the untreated group $(160.3 \pm 2.7 \mathrm{mmHg}, \mathrm{n}=9)$ (Fig. 3A), and HR was lower in treated SHR $(318.8 \pm 5.8 \mathrm{bpm}, \mathrm{n}=9)$ than in untreated SHR (362.7 $\pm 8.3 \mathrm{bpm}, \mathrm{n}=9)$ (Fig. 3B). In contrast, treated and untreated Wistar rats did not differ in terms of SBP or DBP (treated rats: SBP, $121.4 \pm 1.4$; DBP, $87.7 \pm 1.0 \mathrm{mmHg} / \mathrm{min} ; \mathrm{n}=7$; untreated rats: SBP, $123.7 \pm 1$, 2; DBP, $85.9 \pm 1.3 \mathrm{mmHg} / \mathrm{min} ; \mathrm{n}=7$ ). In normotensive Wistar rats, treatment with apocynin did not alter MAP (untreated, $108.3 \pm 1.3$; treated, $108.0 \pm 1.3 \mathrm{mmHg}, \mathrm{n}=9$, Fig. $3 \mathrm{~A}$ ) or HR (untreated, $312.0 \pm 3.4$; treated, $314.2 \pm 4.3 \mathrm{bpm}, \mathrm{n}=9$, Fig. $3 \mathrm{~B}$ ).

Other researchers obtained similar results, treatment with apocynin reduced, but did not normalize SBP values in hypertensive Ang II-infused mice, and this treatment did not affect SBP in normotensive mice [34].

Considering that apocynin significantly affects SBP and MAP in SHR, chronic treatment with $30 \mathrm{mg} / \mathrm{kg}$ apocynin from the 4 th to 10 th week of life could prevent the development of higher blood pressure levels in this experimental model of hypertension.

Our data can be compared to previous results showing that treatment with apocynin at the same dose used in our study ( $30 \mathrm{mg} / \mathrm{kg} /$ day orally), started at the sixth week of age, and maintained for six consecutive 


\section{Untreated Treated}

A

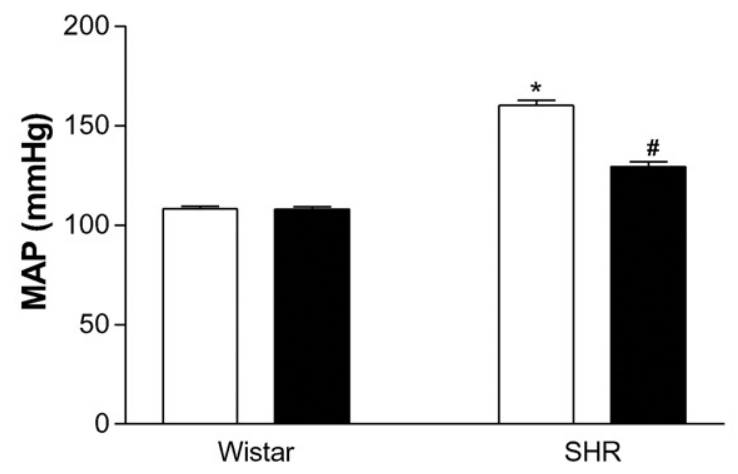

C

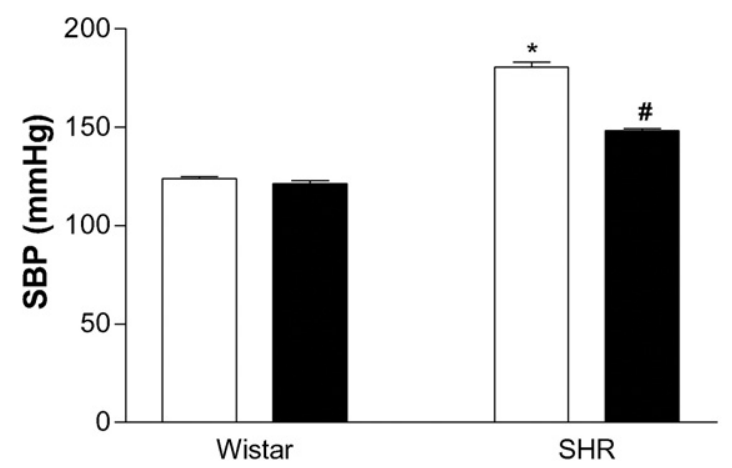

B

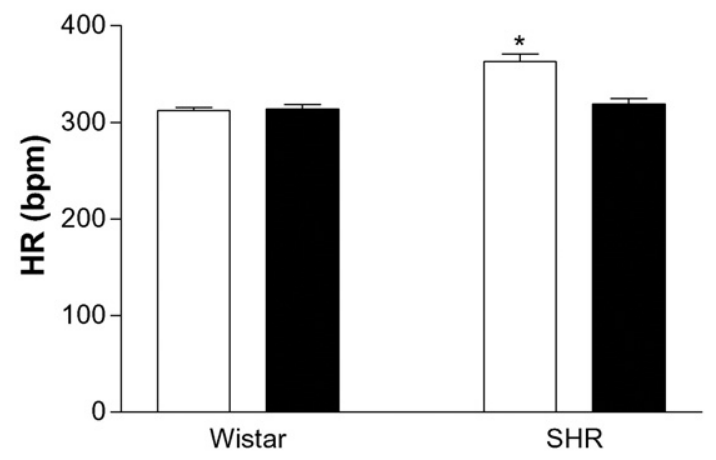

D

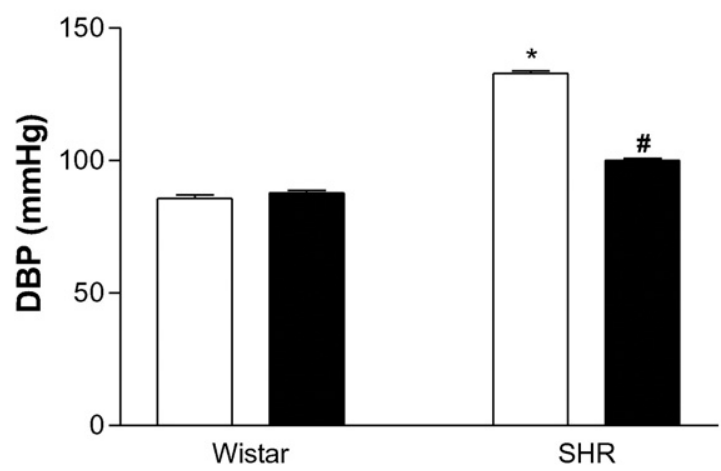

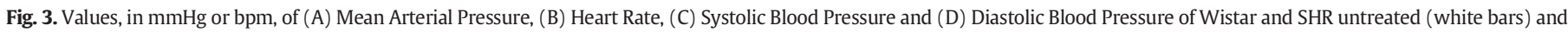

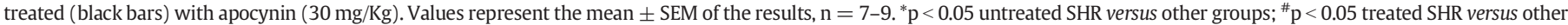
groups (ANOVA).

weeks reduced SBP in SHR at the end of the treatment, but less effectively [28]. The difference between literature results and our data could be associated with the period of treatment. Here, treatment with apocynin began before BP alteration (at the 4th week), whilst Pechanová et al. [28] initiated treatment after observing that BP increased in SHR (at the 6th week). Hypertension was also prevented with $33 \mathrm{mg} / \mathrm{kg}$ apocynin in hypertensive 2 Kidney-1Clip rats [40] and with $1.5 \mathrm{mmol} / \mathrm{L}$ apocynin in fructose-induced hypertension [41] and DOCA-salt rats [42]. Apocynin significantly reduced but did not normalize the higher SBP observed in Ang II-infused mice [34].

Taken together, these data suggest that decreased ROS generation induced by treatment with apocynin might have a critical role in the antihypertensive effect of apocynin observed in different experimental models of hypertension including SHR.

3.4. Apocynin increases the ACh hypotensive effect but does not alter the SNP effect in SHR

Initially, we investigated whether treatment with apocynin could alter the in vivo ACh and SNP effects in SHR. Dose-dependent hypotensive responses to ACh in untreated SHR $(2 \mu \mathrm{g} / \mathrm{kg},-13.8 \pm 1.3 ; 10 \mu \mathrm{g} / \mathrm{kg}$, $-22.6 \pm 1.8$; \% $\triangle \mathrm{MAP} ; \mathrm{n}=7$ ) were lower than the responses obtained in Wistar rats $(2 \mu \mathrm{g} / \mathrm{kg},-28.7 \pm 1.3 ; 10 \mu \mathrm{g} / \mathrm{kg},-39.4 \pm 2.0 ; \% \Delta \mathrm{MAP}$; $\mathrm{n}=7$ ) (Fig. 4A). Apocynin did not alter the ACh hypotensive effect in Wistar rats $(2 \mu \mathrm{g} / \mathrm{kg}$ : treated, $-29.4 \pm 2.3$; untreated, $-28.7 \pm 1.3$; $10 \mu \mathrm{g} / \mathrm{kg}$ : treated, $-40.1 \pm 2.2$; untreated, $-39.4 \pm 2.0 ; \% \Delta \mathrm{MAP}$; $\mathrm{n}=7$ ) (Fig. 3A). However, responses to ACh were greater in treated SHR $(2 \mu \mathrm{g} / \mathrm{kg}:-31.3 \pm 2.6 ; 10 \mu \mathrm{g} / \mathrm{kg},-41.5 \pm 1.9 ; \% \Delta \mathrm{MAP} ; \mathrm{n}=7)$ as compared to untreated SHR $(2 \mu \mathrm{g} / \mathrm{kg}$ : $-13.8 \pm 1.3 ; 10 \mu \mathrm{g} / \mathrm{kg}$ :
$-22.6 \pm 1.8 ; \% \triangle \mathrm{MAP} ; \mathrm{n}=7$ ) (Fig. $4 \mathrm{~A}$ ). The in vivo ACh effects were similar in treated SHR and Wistar rats (Fig. 4A). Apocynin increased the hypotensive responses to ACh (Fig. 4A) in SHR, as observed in $2 \mathrm{~K}$ $1 C$ rats treated with apocynin or tempol [40] or in fructose-induced hypertensive rats treated with apocynin [37].

The SNP hypotensive effect was dose-dependent in all the studied groups. SNP responses in untreated Wistar rats $(10 \mu \mathrm{g} / \mathrm{kg}:-20.2 \pm$ 1.7; $35 \mu \mathrm{g} / \mathrm{kg}:-31.1 \pm 1.1 ; \% \triangle \mathrm{MAP} ; \mathrm{n}=7)$ and SHR $(10 \mu \mathrm{g} / \mathrm{kg}$ : $-19.1 \pm 1.1 ; 35 \mu \mathrm{g} / \mathrm{kg}:-30.4 \pm 1.4 ; \% \triangle \mathrm{MAP} ; \mathrm{n}=7$ ) did not differ (Fig. 4B). Treatment with apocynin did not alter the hypotensive effects of SNP doses in normotensive Wistar rats $(10 \mu \mathrm{g} / \mathrm{kg}:-21.0 \pm 1.5$; $35 \mu \mathrm{g} / \mathrm{kg}:-32.5 \pm 2.0 ; \% \triangle \mathrm{MAP} ; \mathrm{n}=7)$ or in SHR $(10 \mu \mathrm{g} / \mathrm{kg}$ : $-22.5 \pm 1.3 ; 35 \mu \mathrm{g} / \mathrm{kg}:-33.6 \pm 1.3 ; \% \Delta \mathrm{MAP} ; \mathrm{n}=7$ ) (Fig. 4B). Previous studies demonstrated that in vivo SNP responses were higher in SHR than in Wistar rats, suggesting that NO donors affected hypertensive rats to a larger extent [43-45]. However, these studies did not consider differences in basal MAP between normotensive and hypertensive rats before administration of SNP doses. Expression of these results in $\% \triangle \mathrm{MAP}$ did not reveal increased SNP effects in SHR. In our study, the hypotensive responses to SNP did not change in SHR or in Wistar rats treated with apocynin (Fig. 4B), confirming previous results [41,46].

\subsection{Apocynin restores the ACh vasodilator effect on mesenteric resistance arteries and aorta in SHR}

ACh induced concentration-dependent relaxation in mesenteric resistance arteries (2nd and 3rd branches) of untreated Wistar rats (Emax: $91.5 \pm 1.3 \%, \mathrm{n}=5 ; \mathrm{pD}_{2}: 7.8 \pm 0.04, \mathrm{n}=5$, Fig. $5 \mathrm{~A}$ ). In the case of mesenteric arteries of Wistar rats, treatment with apocynin did 
A

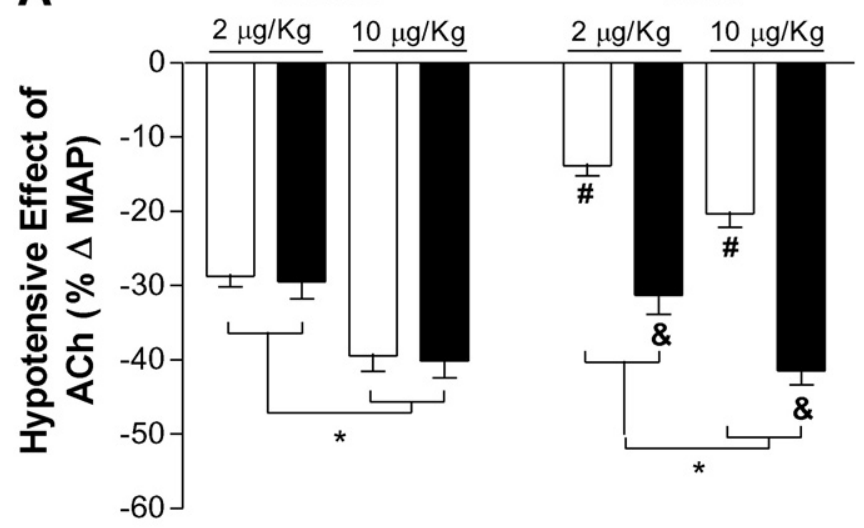

B

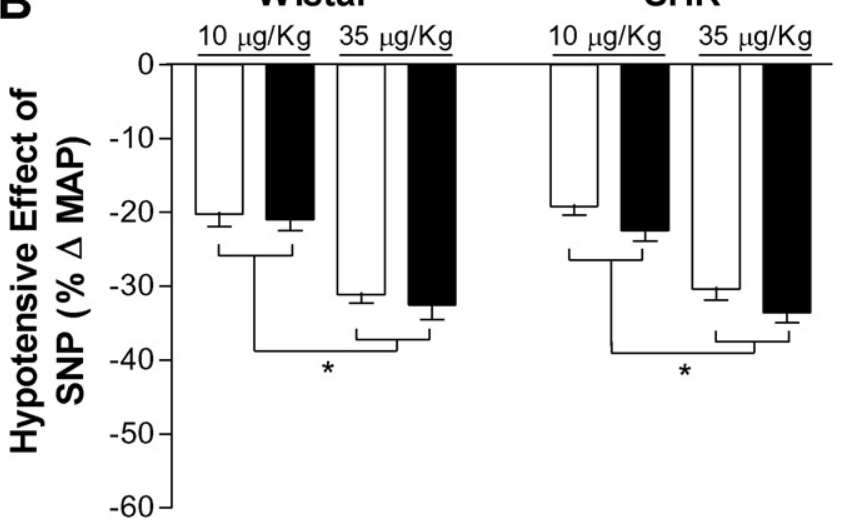

Fig. 4. Percentage of variation of Mean Arterial Pressure (\% $\triangle M A P)$ of Wistar rats and SHR, untreated (white bars) and treated (black bars) with apocynin $(30 \mathrm{mg} / \mathrm{Kg}$ ) after in bolus administration of (A) Acetylcholine (ACh) at 2 and $10 \mu \mathrm{g} / \mathrm{kg}$ and (B) Sodium Nitroprusside (SNP) at 10 and $35 \mu \mathrm{g} / \mathrm{kg}$. Values represent the mean \pm SEM of the results, $\mathrm{n}=7$. ${ }^{*} \mathrm{p}<0.05$ for both doses tested of ACh and SNP; ${ }^{*} \mathrm{p}<0.05$ untreated SHR versus untreated Wistar rats; ${ }^{\&} \mathrm{p}<0.05$ treated SHR versus untreated SHR (ANOVA).

not alter Emax or $\mathrm{pD}_{2}$ values (treated, Emax: $96.0 \pm 1.8 \%, \mathrm{n}=5 ; \mathrm{pD}_{2}$ : $7.4 \pm 0.1, \mathrm{n}=5$ ).

Compared to Wistar rats, ACh vasodilator effects were impaired in mesenteric resistance arteries of untreated SHR (Emax: $72.1 \pm 2.9 \%$, $\mathrm{n}=5 ; \mathrm{pD}_{2}: 7.5 \pm 0.2, \mathrm{n}=5$ ), which suggested endothelial dysfunction. Endothelial dysfunction has been associated with hypertension [11] and is characterized by an imbalance in NO synthesis and/or degradation [47]. Considering the results described above, we hypothesized that treatment with apocynin restores endothelial function in SHR. Treatment with apocynin increased Emax and $\mathrm{pD}_{2}$ of the relaxation curves obtained for ACh (untreated, Emax: $72.1 \pm 2.9 \%, \mathrm{n}=5 ; \mathrm{pD}_{2}: 7.5 \pm$ $0.2, \mathrm{n}=5$; treated, Emax: $97.7 \pm 0.8 \%, \mathrm{n}=5 ; \mathrm{pD}_{2}: 8.3 \pm 0.08, \mathrm{n}=5$ ) in mesenteric resistance arteries of SHR (Fig. 5A). The ACh Emax and $\mathrm{pD}_{2}$ values obtained in mesenteric rings of treated SHR and untreated Wistar rats were similar (Fig. 5A). Apocynin also restored ACh effects in mesenteric resistance arteries of Ang II-infused mouse [34].

Treatment with apocynin led to similar results for SHR aorta (Fig. $5 \mathrm{~B})$. The ACh concentration-effect curves shifted to the right in untreated SHR aorta $\left(\mathrm{pD}_{2}\right.$ : $-7.15 \pm 0.10$; Emax: $\left.109.40 \pm 3.88 \%\right)$ as compared to untreated Wistar rat aorta $\left(\mathrm{pD}_{2}:-8.51 \pm 0.10\right.$; Emax: $102.50 \pm$ $2.60 \%$ ) (Fig. 5B). Apocynin-treated SHR aortas had increased sensitivity to $A C h\left(\mathrm{pD}_{2}\right.$ : $-8.22 \pm 0.16$; Emax: $\left.106.1 \pm 4.45 \%\right)$, as observed in Fig. $5 \mathrm{~B}$. These results agree with the results demonstrated by Wind et al.
A

Mesenteric

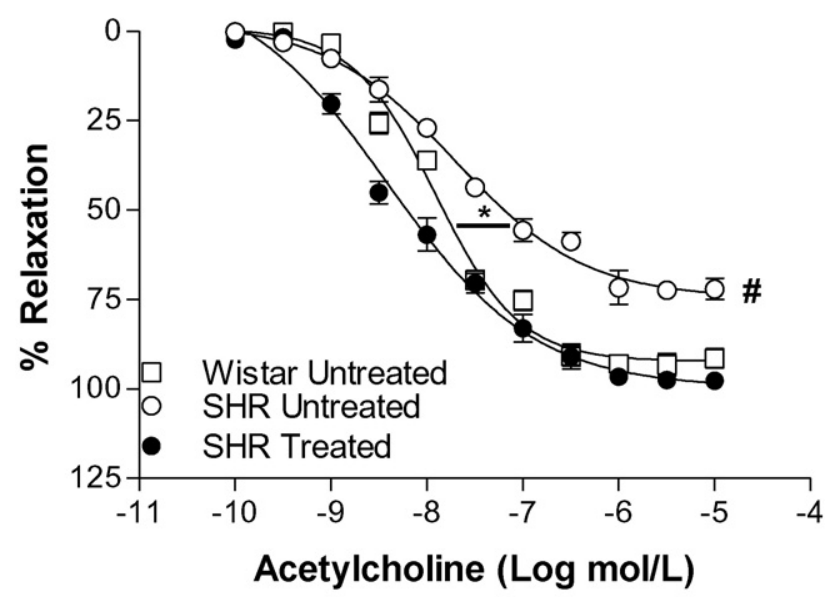

B

Aorta

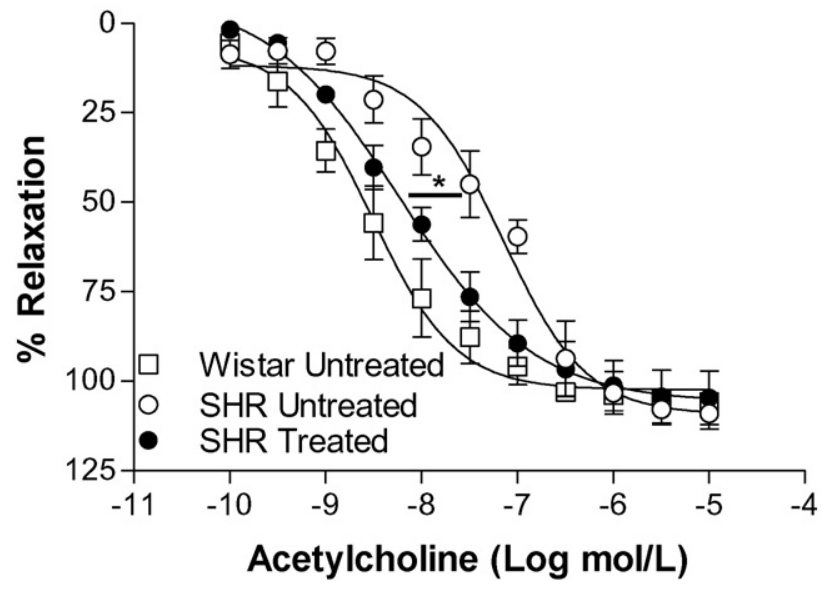

Fig. 5. Relaxation effect, in percentage, of Acetylcholine (ACh, $0.1 \mathrm{nmol} / \mathrm{L}-10 \mu \mathrm{mol} / \mathrm{L}$ ) in rings from $(A)$ the second or the third branches of mesenteric artery and $(B)$ aorta of Wistar rats (white square indicates untreated Wistar rats) and (B) SHR (white circle indicates untreated SHR and black circle indicates treated SHR). Values represent the mean \pm SEM of the results, $n=5$. ${ }^{*} \mathrm{p}<0.05$ for $\mathrm{pD}_{2}$ values in untreated SHR versus other groups; ${ }^{*} \mathrm{p}<0.05$ for Emax values in untreated SHR versus other groups (ANOVA).

[6] in aged SHR aortas. We can suggest that apocynin improves the endothelial function of resistance and conductance arteries in SHR.

3.6. SNP-induced relaxation increases in resistance artery rings containing endothelium of SHR treated with apocynin

In mesenteric resistance artery rings of Wistar rats treated with apocynin or not, the presence of endothelium (untreated, $\mathrm{pD}_{2}: 7.3 \pm$ $0.2, \mathrm{n}=6$; treated, $\mathrm{pD}_{2}: 7.2 \pm 0.2, \mathrm{n}=5$ ) increased SNP potency as compared to rings with no endothelium (untreated, $\mathrm{pD}_{2}: 6.4 \pm 0.1$, $\mathrm{n}=5$; treated, $\mathrm{pD}_{2}: 6.1 \pm 0.1, \mathrm{n}=4$ ). SNP induces NO production by NOS activation in EC of normotensive rat aorta [48]. Bonaventura et al. [48] demonstrated that SNP activates voltage-dependent calcium channels in EC, consequently activating constitutive NOS and increasing NO production, which contributes to relaxation induced by SNP.

The SNP Emax and $\mathrm{pD}_{2}$ values were similar in intact rings of treated and untreated Wistar rats. Rings without endothelium also presented similar $\mathrm{pD}_{2}$ and Emax values (Fig. 6A). Based on these results, apocynin does not alter the SNP effect in mesenteric resistance arteries of Wistar rats. 
A

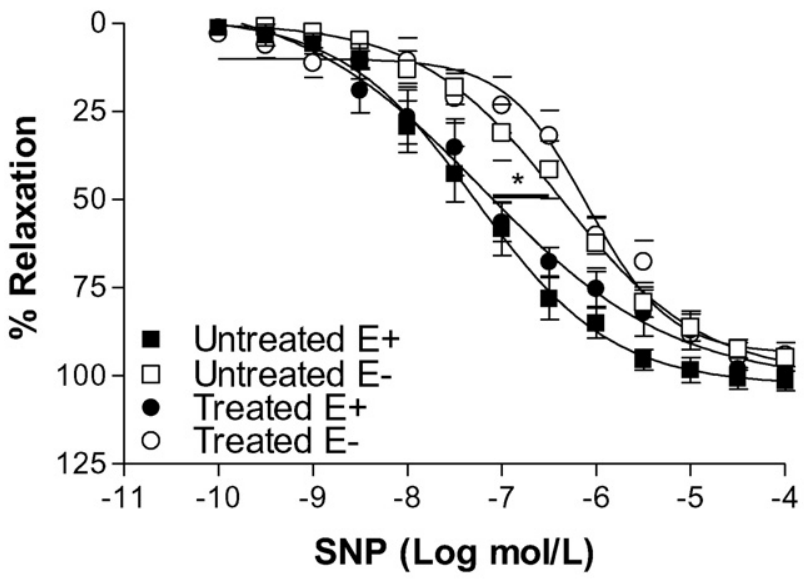

B

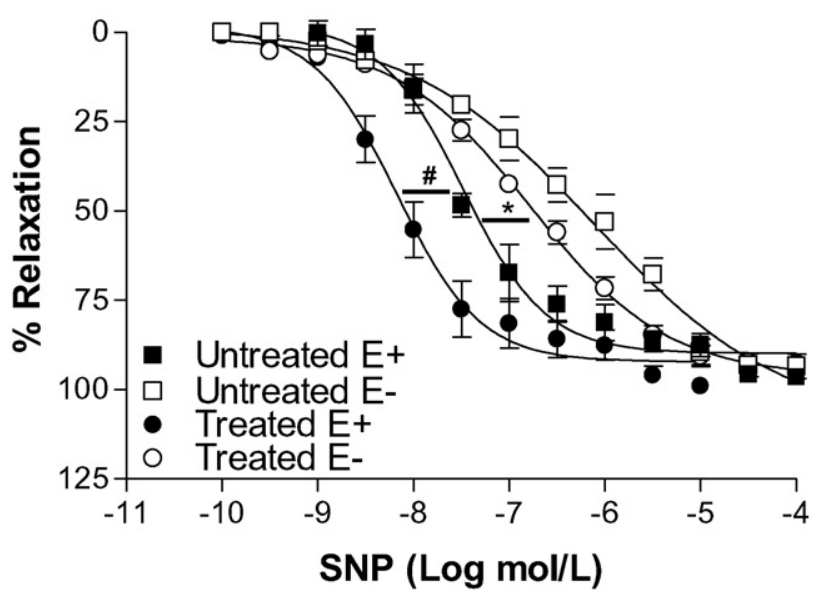

Fig. 6. Relaxation effect, in percentage, of Sodium Nitroprusside (SNP, $0.1 \mathrm{nmol} / \mathrm{L}-$ $100 \mu \mathrm{mol} / \mathrm{L})$ in denuded $(\mathrm{E}-)$ and intact $(\mathrm{E}+)$ endothelium rings from the second and the third branches of mesenteric artery (black square indicates intact endothelium rings of untreated rats; white square indicates denuded rings of untreated rats; black circle indicates intact rings of treated rats; and, white circle indicates denuded rings of treated rats of (A) Wistar rats and (B) SHR. Values represent the mean \pm SEM of the results, $\mathrm{n}=4-6$. ${ }^{*} \mathrm{p}<0.05$ for $\mathrm{pD}_{2}$ values of untreated versus treated groups; ${ }^{\#} \mathrm{p}<0.05$ for $\mathrm{pD}_{2}$ values of untreated SHR E+ versus treated SHR E+ (ANOVA).

For untreated resistance vessels in SHR, the presence of endothelium $(7.4 \pm 0.1, \mathrm{n}=5)$ increased SNP potency in resistance artery rings as compared to rings without endothelium $(6.2 \pm 0.2, \mathrm{n}=5)$. Treated vessels in SHR led to the same results $(E+: 8.1 \pm 0.1, n=5 ; E-: 6.7 \pm 0.1$, $\mathrm{n}=5$ ). Moreover, SNP potency increased significantly in resistance vessels with endothelium in SHR treated with apocynin as compared to the other groups (Fig. 6B). In SHR, treatment with apocynin increased eNOS expression in EC (as demonstrated in Fig. 9), so SNP potency was greater in intact resistance vessels from treated SHR as compared to intact resistance vessels from untreated SHR.

3.7. Apocynin increases endothelial modulation during contractile response induced by PE in aorta of SHR

PE induced contraction in aortic rings of Wistar rats and SHR in a concentration dependent-way (Fig. 7A and B). In aorta of Wistar rats, Emax of contractile response induced by PE was higher in denuded aorta $(3.59 \pm 0.2 \mathrm{~g}, \mathrm{n}=5)$ than in aorta with endothelium $(2.75 \pm$ $0.1 \mathrm{~g}, \mathrm{n}=5$ ). Treatment with apocynin did not change Emax values in
A

Wistar

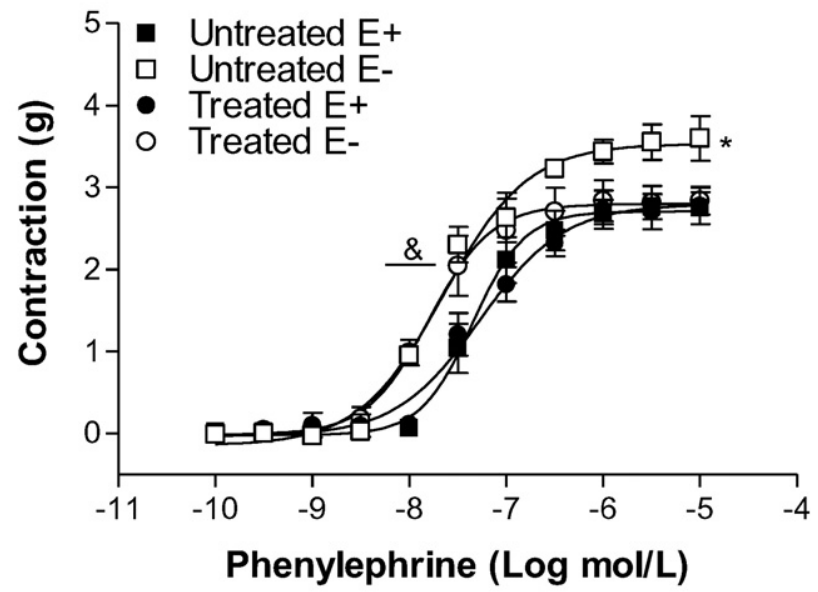

B SHR

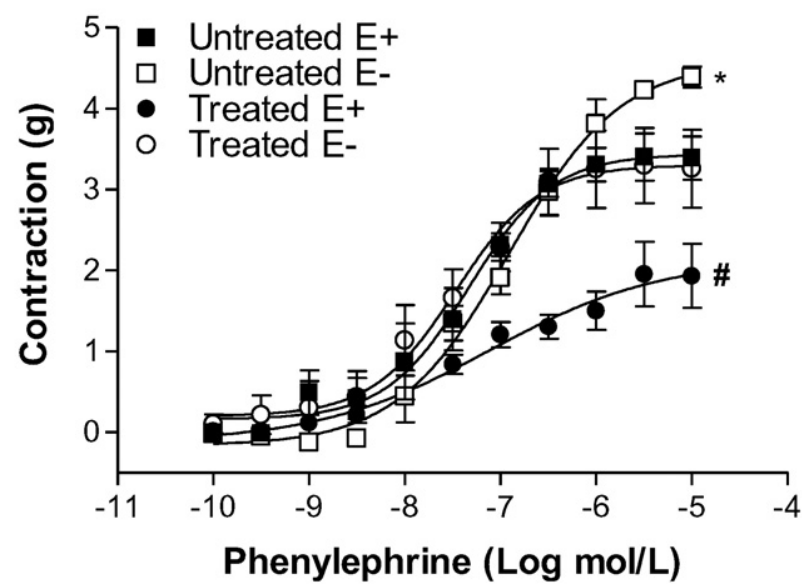

Fig. 7. Constrictor effect, in grams, of Phenylephrine (PE, $0.1 \mathrm{nmol} / \mathrm{L}-10 \mu \mathrm{mol} / \mathrm{L}$ ) in denuded ( $\mathrm{E}-$ ) and intact $(\mathrm{E}+$ ) endothelium aortic rings (black square indicates intact endothelium rings of untreated rats; white square indicates denuded rings of untreated rats; black circle indicates intact rings of treated rats; and, white circle indicates denuded rings of treated rats of (A) Wistar rats and (B) SHR. Values represent the mean \pm SEM of the results, $\mathrm{n}=4-6 .{ }^{*} \mathrm{p}<0.05$ for Emax values of untreated $\mathrm{E}-$ versus other groups; ${ }^{\&} \mathrm{p}<0.05$ for $\mathrm{pD} 2$ values of untreated and treated Wistar rats $\mathrm{E}-$ versus untreated and treated Wistar rat $\mathrm{E}+$; ${ }^{*} \mathrm{p}<0.05$ for Emax values of treated SHR E+ versus other groups (ANOVA).

denuded $(2.77 \pm 0.2 \mathrm{~g}, \mathrm{n}=6)$ or intact aortas $(2.83 \pm 0.1 \mathrm{~g}, \mathrm{n}=6)$ (Fig. 7A).

Aortic rings without endothelium of untreated (Emax: $4.38 \pm 0.1 \mathrm{~g}$, $\mathrm{n}=4$ ) or treated SHR (Emax: $3.25 \pm 0.4 \mathrm{~g}, \mathrm{n}=5$ ) showed increased PE Emax values as compared to aortic rings with endothelium of untreated (Emax: $3.38 \pm 0.2 \mathrm{~g}, \mathrm{n}=5$ ) or treated (Emax: $1.93 \pm 0.3 \mathrm{~g}, \mathrm{n}=5$ ) SHR (Fig. 7B). Interestingly, endothelium blunted the PE concentration-response curves in aortic rings of SHR treated with apocynin. This effect did not occur in intact aorta of untreated SHR.

Until now, results from in vivo and in vitro experiments have shown that treatment with apocynin can reverse impaired NO bioavailability in SHR. Based on these results, we tried to understand the mechanisms involved in the effects of apocynin on SHR.

3.8. Apocynin increases $\left[\mathrm{Ca}^{2+}\right]_{c}$ and $[\mathrm{NO}]_{c}$ and decreases reactive oxygen species $[R O S]_{c}$ in aortic endothelial cells (AEC) of SHR

In this study, the most interesting results concern the effect of apocynin on $\mathrm{Ca}^{2+}$, NO, and ROS levels in SHR AEC. 

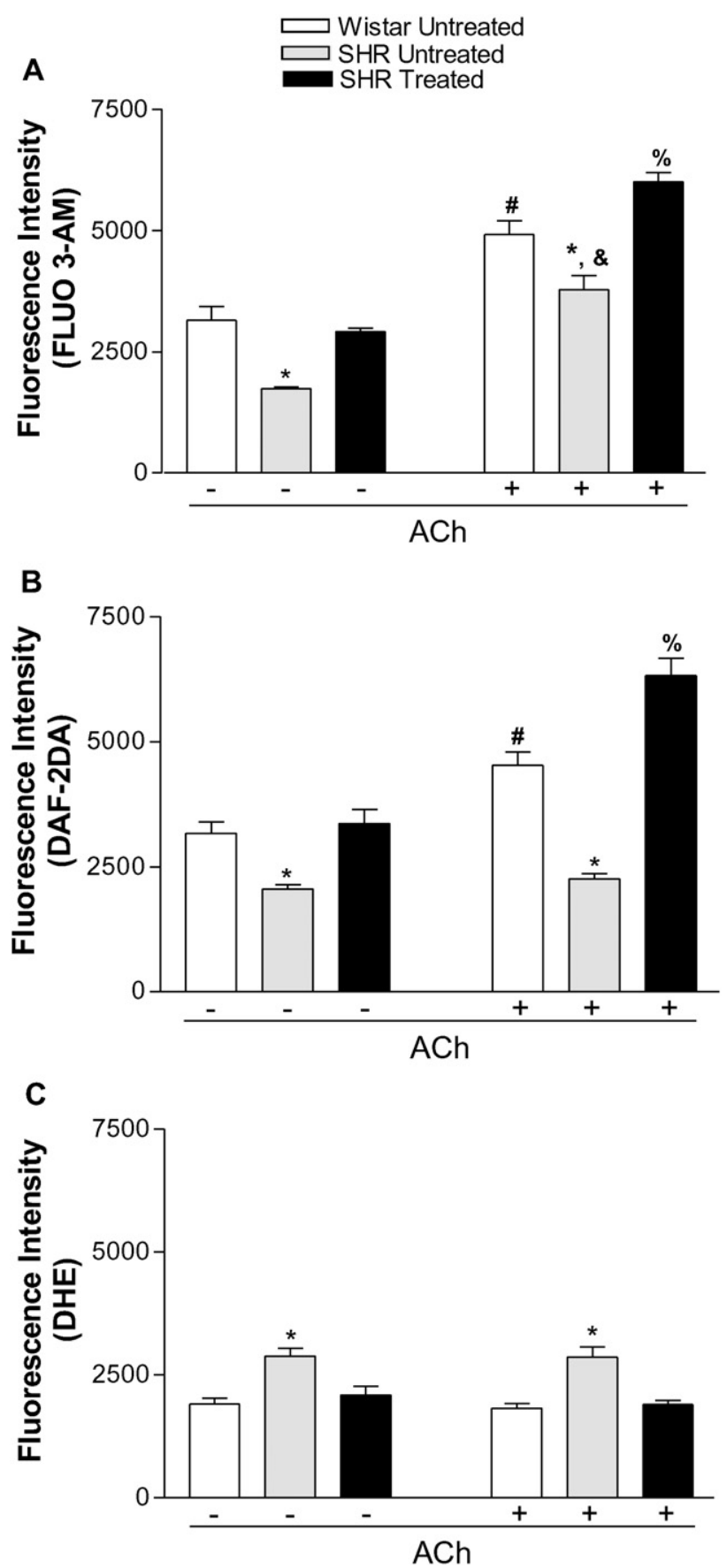

Fig. 8. Fluorescence intensity, in arbitrary units, of (A) FLUO 3-AM, (B) 4,5diaminofluorescein diacetate (DAF 2-DA), and (C) dihydroethidium (DHE) in aortic endothelial cells of untreated Wistar rats (white bars), untreated SHR (gray bars), and treated SHR (black bars) in basal conditions and stimulated with acetylcholine (ACh, $1 \mu \mathrm{mol} / \mathrm{L})$. Values represent the mean \pm SEM of the results, $n=5 .{ }^{*} \mathrm{p}<0.05$ untreated SHR versus other groups; ${ }^{*} \mathrm{p}<0.05$ ACh stimulation versus basal in untreated Wistar rats; ${ }^{\&} \mathrm{p}<0.05$ ACh stimulation versus basal in untreated SHR; ${ }^{\%} \mathrm{p}<0.05$ ACh stimulation versus basal in treated SHR (ANOVA).

SHR AEC had reduced baseline $\left[\mathrm{Ca}^{2+}\right]_{\mathrm{c}}$ (Fig. 8A, 1,743 $\pm 31.0 \mathrm{U}, \mathrm{n}=5$ ) as compared with Wistar rat $\mathrm{AEC}(3148 \pm 287.5 \mathrm{U}, \mathrm{n}=5)$. AEC of treated SHR had higher baseline $\left[\mathrm{Ca}^{2+}\right]_{\mathrm{c}}(2916 \pm 69.0 \mathrm{U}, \mathrm{n}=5)$. ACh stimulation increased $\left[\mathrm{Ca}^{2+}\right]_{\mathrm{c}}$ in all groups, but this effect was more pronounced in AEC of treated SHR $(6005 \pm 189.2 \mathrm{U}, \mathrm{n}=5)$ as compared to AEC of Wistar rats $(4918 \pm 284.2 \mathrm{U}, \mathrm{n}=5)$ or untreated SHR $(3787 \pm 280.1 \mathrm{U}, \mathrm{n}=5)$ (Fig. 8A).

Baseline $[\mathrm{NO}]_{\mathrm{C}}$ (Fig. 8B) in AEC of untreated SHR $(2057 \pm 81.0 \mathrm{U}$, $\mathrm{n}=5$ ) was lower than baseline $[\mathrm{NO}]_{\mathrm{c}}$ in AEC of Wistar rats (3180 \pm
$220.0 \mathrm{U}, \mathrm{n}=5)$ or treated SHR $(3368 \pm 276.0 \mathrm{U}, \mathrm{n}=5)$. AEC of Wistar rats and treated SHR did not differ in terms of $[\mathrm{NO}]_{\mathrm{C}}$. ACh $(1 \mu \mathrm{mol} / \mathrm{L})$ increased $[\mathrm{NO}]_{\mathrm{C}}$ in AEC of Wistar rats $(4526 \pm 263.0 \mathrm{U}, \mathrm{n}=5)$ but not in AEC of untreated SHR ( $2259 \pm 108.0 \mathrm{U}, \mathrm{n}=5)$. However, ACh increased $[\mathrm{NO}]_{\mathrm{c}}$ in AEC of treated SHR $(6320 \pm 345.0 \mathrm{U}, \mathrm{n}=5)$ twice as much as compared to $[\mathrm{NO}]_{\mathrm{c}}$ in AEC of untreated SHR.
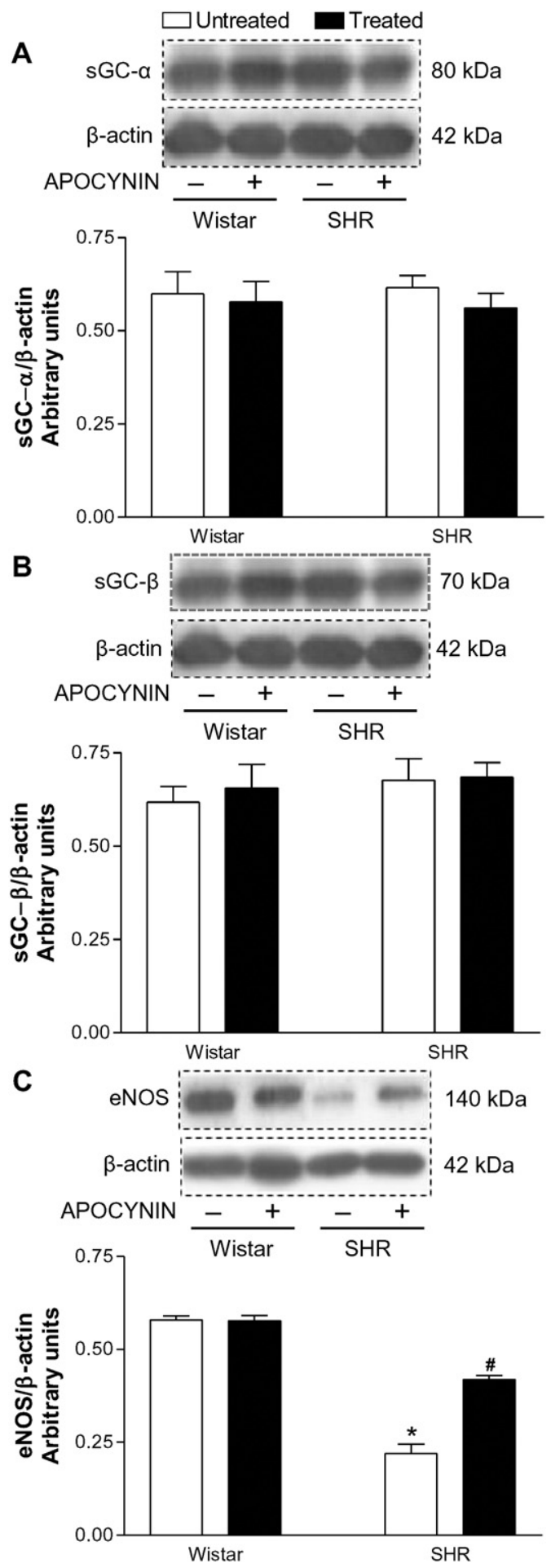

Fig. 9. Typical blots and protein expression, in arbitrary units, of (A) soluble guanylate cyclase alfa subunit (sGC- $\alpha)$, (B) soluble guanylate cyclase beta subunit (sGC- $\beta$ ), and (C) endothelial nitric oxide synthase (eNOS) in aortic homogenates of untreated (white bars) and treated (black bars) Wistar rats and SHR. Values represent the mean \pm SEM of the results, $\mathrm{n}=5$. ${ }^{*} \mathrm{p}<0.05$ untreated SHR versus other groups; ${ }^{*} \mathrm{p}<0.05$ treated SHR versus other groups (ANOVA). 
AEC of untreated SHR (2880 $\pm 155.0 \mathrm{U}, \mathrm{n}=5)$ had higher baseline $[R O S]_{c}$ than AEC of Wistar rats $(1902 \pm 127.0 \mathrm{U}, \mathrm{n}=5)$. Interestingly, AEC of treated SHR presented lower [ROS $]_{\mathrm{C}}$ than AEC of untreated SHR and similar $[\mathrm{ROS}]_{\mathrm{c}}$ to Wistar rats $(2090 \pm 174.0 \mathrm{U}, \mathrm{n}=5)$. ACh did not alter $[R O S]_{C}$ in $A E C$ of treated SHR $(1896 \pm 77.0 \mathrm{U}, \mathrm{n}=5)$, untreated SHR (2858.0 $\pm 256.0 \mathrm{U}, \mathrm{n}=5)$, and Wistar rats $(1822 \pm 95.0 \mathrm{U}, \mathrm{n}=5)$

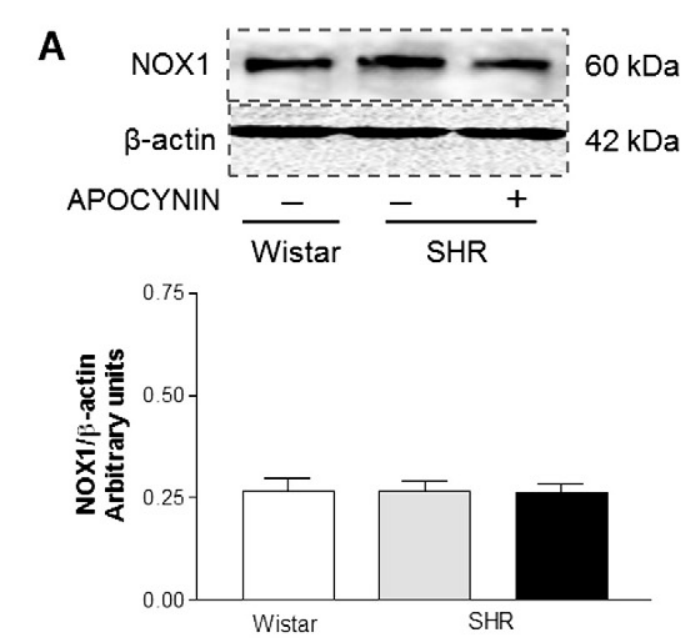

\section{SHR Untreated $\square$ SHR Treated}
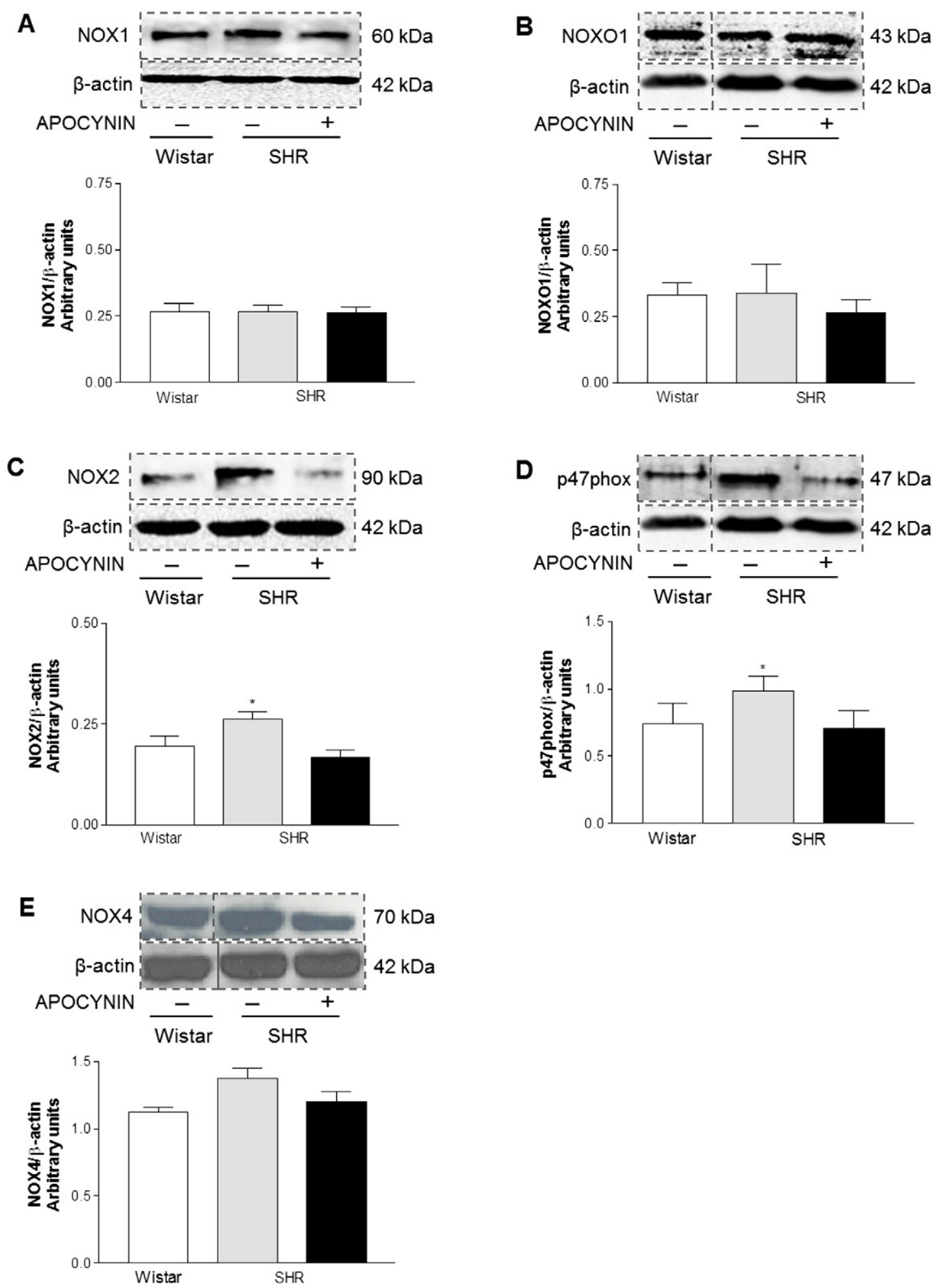

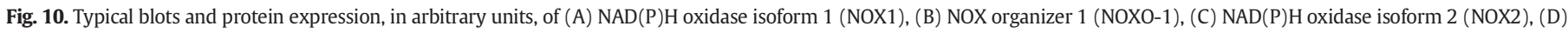

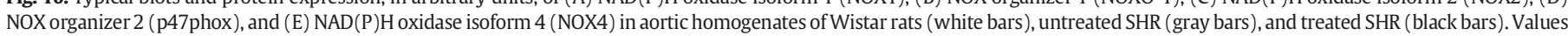
represent the mean \pm SEM of the results. ${ }^{*} \mathrm{p}<0.05$ untreated SHR versus other groups (ANOVA). 
(Fig. 8C). According to previously published results, treatment with apocynin reduced DHE fluorescence in aorta strips of SHR [6] and $\mathrm{O}_{2}^{-}$ in isolated aortic rings of DOCA-salt rats [42].

3.9. Treatment of SHR with apocynin did not alter protein expression of $S G C$ $\alpha$ and $\beta$ subunits, but eNOS expression was higher in SHR aorta homogenates

Wistar rats $(\alpha: 0.60 \pm 0.05 ; \beta: 0.61 \pm 0.04 ; \mathrm{n}=5)$, SHR $(\alpha: 0.61 \pm$ $0.03 ; \beta: 0.67 \pm 0.05 ; n=5)$, treated Wistar rats $(\alpha: 0.57 \pm 0.05 ; \beta$ : $0.65 \pm 0.06 ; \mathrm{n}=5)$, or treated SHR $(\alpha: 0.56 \pm 0.04 ; \beta: 0.68 \pm 0.04$; $\mathrm{n}=5$ ) did not differ in terms of baseline expression of sGC $\alpha$ and $\beta$ subunits (Fig. 9A and B). These results suggested that apocynin does not modify the sensitivity of VSMC to NO because expression of sGC $\alpha$ and $\beta$ subunits in aortic homogenates of Wistar rats and SHR remains the same after treatment. Moreover, knowing that apocynin does not change SNP hypotensive (Fig. 4A and B) or vasodilator (Figs. 5 and 6) effects in SHR, it most likely does not alter vascular smooth muscle sensitivity to NO.

Aorta of SHR $(0.22 \pm 0.02, \mathrm{n}=5)$ had lower baseline eNOS expression than aorta of Wistar rats $(0.58 \pm 0.01, \mathrm{n}=5)$ (Fig. 9C). There were no changes in eNOS expression in aorta of treated Wistar rats $(0.57 \pm$ $0.01, \mathrm{n}=5$ ) as compared to aorta of untreated Wistar rats (Fig. 9C). Aorta of treated SHR exhibited significantly increased eNOS protein expression $(0.41 \pm 0.01, \mathrm{n}=5)$ as compared to aorta of untreated SHR (Fig. 9C). Therefore, according to our results, treatment with apocynin directly influences eNOS expression, which corroborates previous data showing that eNOS activity, measured by [3H]-arginine conversion to $[3 \mathrm{H}]$-citrulline, increases in aortic preparation of SHR treated with apocynin [25].

3.10. Overexpression of NOX2 and the subunit p47phox diminishes in SHR treated with apocynin, but NOX1, NOXO1, and NOX4 expression remains unaltered

NOX1 is regulated [49] and colocalized [50], and it requires NOXO1 for its activation [51] and ROS production [52]. The study groups did not differ with respect to NOX1 (Fig. 10A; untreated Wistar: $0.26 \pm$ 0.03; untreated SHR: $0.26 \pm 0.02$; treated SHR: $0.26 \pm 0.02 ; \mathrm{n}=5$ ) or NOXO1 (Fig. 10B; untreated Wistar: $0.33 \pm 0.04$; untreated SHR: $0.33 \pm 0.11$; treated SHR: $0.26 \pm 0.05 ; \mathrm{n}=5$ ) expression

NOX2 is activated and colocalized with p47phox to assemble the active enzyme, and this interaction is essential for ROS production [4952]. NOX2 (Fig. 10C) was overexpressed in untreated SHR (0.26 \pm $0.03, \mathrm{n}=5)$ as compared to Wistar rats $(0.19 \pm 0.05, \mathrm{n}=5)$. NOX2 expression was higher in aged (12-14 months) SHR aorta [6], vessel walls, kidney, and brain of other hypertension models like Ang II-infused mice [53]. Hence, NOX2 could be involved in hypertension [54] and, once upregulated, could be associated with higher ROS levels in EC of untreated SHR (Fig. 8C).

NOX2 can generate considerably large amounts of ROS, and pharmacological inhibition or genetic deletion of NOX2 or p47phox subunits reduces vascular oxidative stress in several disease models [55]. SHR treated with apocynin had reduced NOX2 expression $(0.16 \pm 0.04$, $\mathrm{n}=5$ ) as compared to untreated SHR. Treatment with apocynin reduced $\mathrm{p} 47 \mathrm{phox}$ expression in aorta of $\operatorname{SHR}(0.70 \pm 0.12, \mathrm{n}=5)$ as compared to aorta of untreated SHR (Fig. 10D; $0.98 \pm 0.11, \mathrm{n}=5$ ). Aortas of treated SHR $(0.70 \pm 0.12, \mathrm{n}=5)$ and untreated Wistar rats $(0.74 \pm$ $0.14, \mathrm{n}=5$ ) had similar p47phox expression. Stolk et al. [56] described that apocynin directly interacts with p47phox, preventing p47phox translocation and inhibiting NOX. Here, apocynin reduced NOX2 and p47phox expression in aorta and reduced ROS concentration in EC of SHR.

NOX4 is constitutively active and does not require regulatory subunits for activation. Its regulation occurs through changes in expression levels [57]. Most probably, NOX4 is not a major regulator of blood pressure, since NOX4 knockout mice do not have significantly different basal blood pressure [58], not to mention that elevated NOX4 expression in vasculature of experimental models of hypertension is controversial [59-61]. NOX4 expression did not change in aorta of aged SHR [6]. Herein, NOX4 expression in aorta of untreated (untreated: $1.37 \pm$ $0.07, \mathrm{n}=5)$ and treated $(1.20 \pm 0.07, \mathrm{n}=5$, Fig. 10E) SHR did not change as compared to aorta of Wistar rats (untreated Wistar: $0.12 \pm$ $0.03, \mathrm{n}=5$ ). Hence, NOX4 may be not be involved in hypertension or in any apocynin effect.

\section{Conclusions}

This study has demonstrated that apocynin can reduce blood pressure and prevent development of endothelial dysfunction in SHR. According to our results, treatment with apocynin effectively normalizes high systemic and cellular ROS in SHR, reaching the physiological levels observed in Wistar rats. Apocynin increases $\mathrm{Ca}^{2+}$ and NO the concentration in aortic endothelial cells and eNOS expression in aorta of SHR, suggesting increased eNOS activity. Moreover, apocynin returns expression of NOX2 and its subunit p47phox to normal levels in aorta of SHR. Taken together, the results presented in this study suggest that apocynin increases NO biovailability by different mechanisms, restoring the proper function of vascular endothelium in SHR.

\section{Conflict of interest}

The authors declare that there are no conflicts of interest.

\section{Funding}

This research was supported by Fundação de Amparo à Pesquisa do Estado de São Paulo (FAPESP), process numbers 2011/04619-0, 2011/ 19859-6, 2012/01733-9, and 2011/20998-0.

\section{Acknowledgments}

The authors thank Prof. Dr. João Carlos Callera for allowing the use of the equipment for direct recording of blood pressure (in vivo experiments) and Prof. Dr. Tereza Cristina Cardoso Silva for allowing the use of the flow cytometry equipment.

\section{References}

[1] H. Cai, D.G. Harrison, Endothelial dysfunction in cardiovascular diseases: the role of oxidant stress, Circ. Res. 87 (10) (2000) 840-844.

[2] B.M. Babior, NADPH oxidase, Curr. Opin. Immunol. 16 (1) (2004) 42-47.

[3] M. Geiszt, NADPH oxidases: new kids on the block, Cardiovasc. Res. 71 (2) (2006) 289-299.

[4] B. Lassègue, R.E. Clempus, Vascular NAD(P)H oxidases: specific features, expression, and regulation, Am. J. Physiol. Regul. Integr. Comp. Physiol. 285 (2) (2003) R277-R297.

[5] T.M. Paravicini, S. Chrissobolis, G.R. Drummond, et al., Increased NADPH-oxidase activity and Nox4 expression during chronic hypertension is associated with enhanced cerebral vasodilatation to NADPH in vivo, Stroke 35 (2) (2004) 584-589.

[6] S. Wind, K. Beuerlein, M.E. Armitage, et al., Oxidative stress and endothelial dysfunction in aortas of aged spontaneously hypertensive rats by NOX1/2 is reversed by NADPH oxidase inhibition, Hypertension 56 (3) (2010) 490-497.

[7] B. Lassègue, A. San Martín, K.K. Griendling, et al., Biochemistry, physiology, and pathophysiology of NADPH oxidases in the cardiovascular system, Circ. Res. 110 (10) (2012) 1364-1390.

[8] C.A. Hamilton, M.J. Brosnan, M. McIntyre, et al., Superoxide excess in hypertension and aging: a common cause of endothelial dysfunction, Hypertension 37 (2) (2001) 529-534.

[9] D. Salvemini, Z.Q. Wang, M.K. Stern, et al., Peroxynitrite decomposition catalysts: novel therapeutics for peroxynitrite-mediated pathology, Proc. Natl. Acad. Sci. U. S. A. 95 (1998) 2659-2663.

[10] M.C. Gongora, D.G. Harrison, Sad heart from no SOD, Hypertension 51 (1) (2008) 28-30.

[11] M. McIntyre, D.F. Bohr, A.F. Dominiczak, Endothelial function in hypertension: the role of superoxide anion, Hypertension 34 (4) (1999) 539-545.

[12] T.J. Rabelink, T.F. Lüscher, Endothelial nitric oxide synthase: host defense enzyme of the endothelium? Arterioscler. Thromb. Vasc. Biol. 26 (2) (2006) 267-271. 
[13] G. Zalba, F.J. Beaumont, G. San José, et al., Vascular NADH/NAD(P)H oxidase is involved in enhanced superoxide production in spontaneously hypertensive rats, Hypertension 35 (5) (2000) 1055-1061.

[14] T.F. Lüscher, P.M. Vanhoutte, Endothelium - dependent contractions to acetylcholine in the aorta of the spontaneously hypertensive rat, Hypertension 8 (4) (1986) 344-348.

[15] K. Miyagawa, M. Ohashi, S. Yamashita, et al., Increased oxidative stress impairs endothelial modulation of contractions in arteries from spontaneously hypertensive rats, J. Hypertens. 25 (2) (2007) 415-421.

[16] D. Dobarro, M.C. Gómez-Rubín, A. Sanchez-Recalde, et al., Current pharmacological approach to restore endothelial dysfunction, Cardiovasc. Hematol. Agents Med. Chem. 7 (3) (2009) 212-222.

[17] E. Aldieri, C. Riganti, M. Polimeni, et al., Classical inhibitors of NOX NAD(P)H oxidases are not specific, Curr. Drug Metab. 9 (8) (2008) 686-696.

[18] R.M. Touyz, E.L. Schiffrin, Reactive oxygen species in vascular biology: implications in hypertension, Histochem. Cell Biol. 122 (4) (2004) 339-352.

[19] D.K. Johnson, K.J. Schillinger, D.M. Kwait, et al., Inhibition of NADPH oxidase activation in endothelial cells by ortho-methoxy-substituted catechols, Endothelium 9 (3) (2002) 191-203.

[20] V.F. Ximenes, M.P. Kanegae, S.R. Rissato, et al., The oxidation of apocynin catalyzed by myeloperoxidase: proposal for NADPH oxidase inhibition, Arch. Biochem. Biophys. 457 (2) (2007) 134-141.

[21] J. Stolk, T.J. Hiltermann, J.H. Dijkman, et al., Characteristics of the inhibition of NADPH oxidase activation in neutrophils by apocynin, a methoxy-substituted catechol, Am. J. Respir. Cell Mol. Biol. 11 (1) (1994) 95-102.

[22] J.M. Astern, W.F. Pendergraft III, R.J. Falk, et al., Myeloperoxidase interacts with endothelial cell-surface cytokeratin 1 and modulates bradykinin production by the plasma Kallikrein-Kinin system, Am. J. Pathol. 171 (1) (2007) 349-360.

[23] S. Heumüller, S. Wind, E. Barbosa-Sicard, et al., Apocynin is not an inhibitor of vascular NADPH oxidases but an antioxidant, Hypertension 51 (2) (2008) 211-217.

[24] R.M. Touyz, Apocynin, NADPH oxidase and vascular cells: a complex matter, Hypertension 51 (2) (2008) 172-174.

[25] A.T. Bäumer, C.A. Krüger, J. Falkenberg, et al., The NAD(P)H oxidase inhibitor apocynin improves endothelial NO/superoxide balance and lowers effectively blood pressure in spontaneously hypertensive rats: comparison to calcium channel blockade, Clin. Exp. Hypertens. 29 (5) (2007) 287-299.

[26] T. Schlüter, A.C. Steinbach, A. Steffen, et al., Apocynin-induced vasodilation involves Rho kinase inhibition but not NADPH oxidase inhibition, Cardiovasc. Res. 80 (2008) 271-279.

[27] Y.L. Tain, C.N. Hsu, L.T. Huang, et al., Apocynin attenuates oxidative stress and hypertension in young spontaneously hypertensive rats independent of ADMA/NO pathway, Free Radic. Res. 46 (1) (2012) 68-76.

[28] O. Pechanová, L. Jendeková, S. Vranková, Effect of chronic apocynin treatment on nitric oxide and reactive oxygen species production in borderline and spontaneous hypertension, Pharmacol. Rep. 61 (1) (2009) 116-122.

[29] J.A. Buege, S.D. Aust, Microsomal lipid peroxidation, Methods Enzymol. 52 (1978) 302-310.

[30] S.R. Potje, F.C. Munhoz, L.A. Perassa, et al., Mechanisms underlying the hypotensive and vasodilator effects of Ru(terpy)(bdq)NO ${ }^{3+}$, a nitric oxide donor, differ between normotensive and spontaneously hypertensive rats, Eur. J. Pharmacol. 741 (2014) 222-229.

[31] O.H. Lowry, N.J. Roserbrough, A.L. Farr, et al., Protein measurement with the Folin phenol reagent, J. Biol. Chem. 193 (1951) 265-275.

[32] M.J. Mulvany, W. Halpern, Contractile properties of small arterial resistance vessels in spontaneously hypertensive and normotensive rats, Circ. Res. 41 (1) (1977) 19-26.

[33] J.A. Troiano, S.R. Potje, M.E. Graton, Decreased reactive oxygen species production and NOX1, NOX2, NOX4 expressions contribute to hyporeactivity to phenylephrine in aortas of pregnant SHR, Life Sci. 144 (2016) 178-184.

[34] A. Virdis, M.F. Neves, F. Amiri, et al., Role of NAD(P)H oxidase on vascular alterations in angiotensin II-infused mice, J. Hypertens. 22 (2004) 535-542.

[35] S. Lavi, E.H. Yang, A. Prasad, et al., The interaction between coronary endothelial dysfunction, local oxidative stress, and endogenous nitric oxide in humans, Hypertension 51 (2008) 127-133.

[36] J. Jun, V. Savransky, A. Nanayakkara, et al., Intermittent hypoxia has organ-specific effects on oxidative stress, Am. J. Physiol. Regul. Integr. Comp. Physiol. 295 (2008) R1274-R1281.

[37] S.D. Gray, Pressure profiles in neonatal spontaneously hypertensive rats, Biol. Neonate 45 (1) (1984) 25-32.
[38] F.J. Jr Clubb, P.D. Bell, J.D. Kriseman, et al., Myocardial cell growth and blood pressure development in neonatal spontaneously hypertensive rats, Lab. Investig. 56 (2) (1987) 189-197.

[39] J.G. Dickhout, R.M.K.W. Lee, Blood pressure and heart rate development in young spontaneously hypertensive rats, Am. J. Phys. 274 (3) (1998) H794-H800.

[40] C.A. Costa, T.A. Amaral, L.C. Carvalho, et al., Antioxidant treatment with tempol and apocynin prevents endothelial dysfunction and development of endovascular hypertension, Am. J. Hypertens. 22 (12) (2009) 1242-1249.

[41] B.S. Unger, B.M. Patil, Apocynin improves endothelial function and prevents the development of hypertension in fructose fed rat, Indian J. Pharmacol. 41 (5) (2009) 208-212.

[42] R.A. Beswick, A.M. Dorrance, R. Leite, et al., NADH/NADPH oxidase and enhanced superoxide production in the mineralocorticoid hypertensive rat, Hypertension 38 (5) (2001) 1107-1111.

[43] C.M. de Gaitani, M.C. de Melo, C.N. Lunardi, et al., Hypotensive effect of the nitrosyl ruthenium complex nitric oxide donor in renal hypertensive rats, Nitric Oxide 20 (2009) 195-199

[44] B.F. de Barros, J.C. Toledo, D.W. Franco, et al., A new inorganic vasodilator, trans$\left[\mathrm{Ru}(\mathrm{NO})\left(\mathrm{NH}_{3}\right)_{4}(\mathrm{POEt})_{3}\right]\left(\mathrm{PF}_{6}\right)_{3}$ : hypotensive effect of endothelium-dependent and independent vasodilators in different hypertensive animals models, Nitric Oxide 7 (2002) 50-56.

[45] F.C. Munhoz, S.R. Potje, A.C. Pereira, et al., Hypotensive and vasorelaxing effects of the new $\mathrm{NO}$ donor $[\mathrm{Ru}($ terpy)(bdq) $\mathrm{NO}(+)](3+)$ in spontaneously hypertensive rats, Nitric Oxide 26 (2012) 111-117.

[46] D.A. Rizzetti, J.G. Torres, A.G. Escobar, et al., Apocynin prevents vascular effects caused by chronic exposure to low concentrations of mercury, PLoS One 8 (2) (2013) 1-12.

[47] D.D. Rees, R.M. Palmer, S. Moncada, Role of endothelium-derived nitric oxide in the regulation of blood pressure, Proc. Natl. Acad. Sci. U. S. A. 86 (9) (1989) 3375-3378

[48] D. Bonaventura, C.N. Lunardi, G.J. Rodrigues, et al. A novel mechanism of vascula relaxation induced by sodium nitroprusside in the isolated rat aorta, Nitric Oxide 18 (2008) 287-295.

[49] T.J. Guzik, S. Mussa, D. Gastaldi, et al., Mechanisms of increased vascular superoxide production in human diabetes mellitus: role of $\mathrm{NAD}(\mathrm{P}) \mathrm{H}$ oxidase and endothelial nitric oxide synthase, Circulation 105 (2002) 1656-1662.

[50] K.L. Siu, L. Gao, H. Cai, Differential roles of NOX1/NOXO1 and NOX2/p47phox in mediating endothelial redox responses to oscillatory and unidirectional laminar shear stress, J. Biol. Chem. 1-22 (2016).

[51] A.C. Montezano, R.M. Touyz, Reactive oxygen species, vascular Noxs, and hypertension: focus on translational and clinical research, Antioxid. Redox Signal. 20 (2014) 164-182.

[52] S. Selemidis, C.G. Sobey, K. Wingler, et al., NADPH oxidases in the vasculature: molecular features, roles in disease and pharmacological inhibition, Pharmacol. Ther. 120 (2008) 254-291.

[53] M.E. Cifuentes, F.E. Rey, O.A. Carretero, et al., Upregulation of p67(phox) and gp91(phox) in aortas from angiotensin ii-infused mice, Am. J. Physiol. Heart Circ. Physiol. 279 (2000) H2234-H2240.

[54] B. Lasségue, A. San Martín, K.K. Griendling, Biochemistry, physiology, and pathophysiology of NADPH oxidases in the cardiovascular system, Circ. Res. 110 (2012) 1364-1390.

[55] G.R. Drummond, S. Selemidis, K.K. Griendling, Combating oxidative stress in vascular disease: NADPH oxidases as therapeutic targets, Nat. Rev. Drug Discov. 10 (2011) 453-471.

[56] J. Stolk, T.J.N. Hiltermann, J.H. Dijkman, et al., Characteristics of the inhibition of NADPH oxidase activation in neutrophils by apocynin, a methoxy-substituted catechol, Am. J. Respir. Cell Mol. Biol. 11 (1994) 95-102.

[57] A. Sirker, M. Zhang, A.M. Shah, NADPH oxidases in cardiovascular disease: insight from in vivo models and clinical, Basic Res. Cardiol. 106 (2011) 735-747.

[58] H. Schmidt, J. Hermans, P. Schiffers, et al., NADPH oxidase as a pharmacological target in disease-relevant oxidative stress, Acta Physiol. 203 (Suppl. 687) (2011) (O22).

[59] K. Wingler, S. Wunsch, R. Kreutz, et al., Upregulation of the vascular NAD(P)H-oxidase isoforms nox 1 and nox 4 by the renin-angiotensin system in vitro and in vivo, Free Radic. Biol. Med. 31 (2001) 1456-1464.

[60] H. Mollnau, M. Wendt, K. Szocs, et al, Effects of angiotensin ii infusion on the expression and function of $\mathrm{NAD}(\mathrm{P}) \mathrm{H}$ oxidase and components of nitric oxide/cgmp signaling, Circ. Res. 90 (2002) E58-E65.

[61] T. Akasaki, Y. Ohya, J. Kuroda, et al., Increased expression of gp91phox homologues of $\mathrm{NAD}(\mathrm{P}) \mathrm{H}$ oxidase in the aortic media during chronic hypertension: involvement of the renin-angiotensin system, Hypertens. Res. 29 (2006) 813-820. 